\title{
A Multi-objective Evolutionary Algorithm Based on Coordinate Transformation
}

\author{
Wei Fang, Member, IEEE, Lingzhi Zhang, Shengxiang Yang Senior Member, IEEE, Jun Sun, Xiaojun Wu
}

\begin{abstract}
In this paper, a novel multi-objective evolutionary algorithm (called MOEA/CT) is proposed for better managing convergence and distribution of solutions when multi-objective evolutionary algorithms (MOEAs) are used for solving multiobjective optimization problems (MOPs). The coordinate transformation strategy, an external archive update strategy, and a diversity maintenance strategy are proposed in MOEA/CT. The coordinate transformation strategy in the objective space is designed for finding more efficient solutions that can accelerate the convergence process. Based on the coordinate transformation strategy, a novel update strategy and diversity maintenance approach for selecting non-dominated solutions from the external archive set are integrated in MOEA/CT for getting better distribution of the solutions. The proposed MOEA/CT is compared with eight state-of-art algorithms on six bi-objective and seven triobjective test problems. In terms of four performance metrics, the comparative experimental results demonstrate that MOEA/CT outperforms the other eight competitors and it can achieve solutions with better distribution and better convergence to the Pareto front. Additionally, a parameter sensitivity analysis is provided to investigate the effect of a key parameter in MOEA/CT; the proposed three strategies are also studied individually to investigate their contribution in MOEA/CT; the performance analysis along with the capacity of external archive is given to make clear the influence in MOEA/CT; finally, the scalability performance of MOEA/CT is investigated and compared with five notable many-objective evolutionary algorithms on the DTLZ and WFG test suites with $5,8,10$, and 15 objectives.
\end{abstract}

Index Terms-evolutionary algorithm, multi-objective optimization, coordinate transformation.

\section{INTRODUCTION}

Multi-objective optimization (MOO) concerns with optimization problems that have more than one objective function to be optimized simultaneously. The objectives in MOO are usually conflicting and competing with each other and the optimal solutions should consider the tradeoffs between the conflicting objectives. Multi-objective optimization problems

Manuscript received November 16, 2017; revised March 15, 2018; accepted May 3, 2018. This work was supported in part by the National Natural Science foundation of China (Grant Nos. 61673194, 61672263, 61105128), Key Research and Development Program of Jiangsu Province, China (Grant No. BE2017630), the Postdoctoral Science Foundation of China (Grant No. 2014M560390), Six Talent Peaks Project of Jiangsu Province (Grant No. DZXX-025).

W. Fang, J. Sun, X. Wu are with the Jiangsu Provincial Engineering Laboratory of Pattern Recognition and Computational Intelligence, Department of Computer Science and Technology, Jiangnan University, Wuxi, China. Email: fangwei@jiangnan.edu.cn, sunjun_wx@hotmail.com, wu_xiaojun@jiangnan.edu.cn.

L. Zhang is with the Network Information and Operation Center, Jiangnan University, Wuxi, China. Email: zhanglingzhi@jiangnan.edu.cn

S. Yang is with the Centre for Computational Intelligence (CCI), School of Computer Science and Informatics, De Montfort University, Leicester LE1 9BH, UK. Email: syang@dmu.ac.uk.
(MOPs) [8], [39], [70] arise in many fields, such as finance, economics, optimal control and design, electric power systems, etc. Solving MOPs is to find a set of trade-off solutions, known as Pareto-optimal solutions, which can make a compromise among all the objectives and constraints. Multi-objective Optimization Evolutionary Algorithms (MOEAs) have been suggested to solve MOPs since they can find a set of Paretooptimal solutions in a single run [5], [19].

In recent years, many new evolutionary mechanisms have been introduced to MOEAs to get better performance for MOPs. The major MOEAs can be classified into three types in general, which are Pareto dominance based algorithms, performance indicator based algorithms, and decomposition based algorithms. Pareto dominance based MOEAs are one of the most popular approaches for MOPs in the past several years, which are good at solving MOPs with two or three objectives. The non-dominated sorting genetic algorithm (NSGA) is one of the early proposed Pareto dominance based MOEAs [41]. Deb et al. presented a fast elitist non-dominated sorting genetic algorithm II (NSGA-II) [16] with much better performance than its previous version. NSGA-II uses a selection operator to select the best solutions by combining the parent and offspring populations in the mating pool. The introduction of elitism in NSGA-II has helped the algorithm to achieve better convergence. The computational complexity is greatly reduced by a fast non-dominated sorting approach. However, the elite strategy makes it easy for NSGA-II to focus on the nondominated solutions far away from the Pareto front (PF), to a certain extent, which limits the search performance of NSGAII. In view of the deficiency of NSGA-II, NSGA-III [15] was proposed, which is a reference-point-based many-objective evolutionary algorithm following the NSGA-II framework that emphasize population members that are non-dominated, yet close to a set of supplied reference points. In order to reduce the cost of maintaining the nondominated levels (NDL) in NSGA-II, Li et. al designed an efficient NDL update approach [31]. Zitzler et. al proposed the Strength Pareto evolutionary algorithm (SPEA) [69] and its improved version SPEA2 [68] for finding the Pareto optimal set for MOPs. In [60], a knee point-driven evolutionary algorithm is proposed to solve MOPs. Knee points are naturally most preferred among nondominated solutions if there is no explicit user preferences. A bias toward the knee points in the non-dominated solutions in the current population is shown to be an approximation of a bias toward a large hypervolume, thereby enhancing the convergence performance.

As the dominate control method is concerned, researchers have proposed a number of improved measures. A Shift- 
based density estimation (SDE) strategy [33] was presented, which can adjust the distance between the adjacent individuals and take the adjusted distance as the parameter for density estimation. Similar with the $\theta$-dominance in [55], an efficient non-dominated sorting (ENS) [61] was proposed for MOPs, which uses a solution to be assigned to a front according to demand and then divides the individuals into several regions with different levels which can avoid the unnecessary dominance comparisons. The ENS reduces the computational complexity greatly, but the use of different search strategies has a certain impact on the scale of the solutions. An MOEA based on information separation (ISEA) proposed in [64] uses a fixed hyper plane through an inclined angle to realize the separation of individual information. Furthermore, by using the neighborhood penalty mechanism of hierarchical selection, the elite individuals are selected to make good distribution of the population.

Since Zhang and Li introduced decomposition strategy into MOEAs in 2007 [59] and proposed a multi-objective evolutionary algorithm based on decomposition (MOEA/D), MOEA/D has attracted wide attention in terms of the decomposition approaches, dominance approaches, weight vector generation approaches, etc. [44]. MOEA/D decomposes a multi-objective optimization problem into a number of scalar optimization subproblems and optimizes the individual objectives simultaneously. Each subproblem is optimized by using the information from its several neighboring subproblems. Hence, MOEA/D can well deal with disparately-scaled objectives. In [12], an internal population and an external archive strategy were employed in MOEA/D for handling multi-objective combinatorial optimization. For solving manyobjective optimization problems by MOEA/D, several strategies, such as two kinds of adjustments [10] and decompositionbased-sorting and angle-based-selection [11], have been proposed to balance convergence and diversity among the subproblems. In [49], an improved decomposition approach was designed for MOEA/D by imposing constraints on different subproblems. Zhou et al. studied a novel resource allocation strategy for MOEA/D by using a probability of improvement vector instead of the equally allocation strategy [65]. For solving MOPs with complex Pareto fronts, computational resources allocation approach and new niche scheme in two phases are incorporated with MOEA/D [24]. Yang et al. improved two novel penalty boundary intersection schemes for decomposition in MOEA/D [52]. In order to balance between convergence and diversity in MOEA, two kinds of stable matching-based selection mechanisms and the combination of dominance and decomposition were implemented in MOEA/D in [50] and [30] respectively. By dividing the whole objective space uniformly into several subspaces with regarding to the set of weight vectors, a decomposition-based archiving approach for MOEA was proposed in [63].

As performance indicator based algorithms are concerned, the main motivation to use different performance indicators to guide the optimization process. In [67] and [9], a general indicator based evolutionary algorithm (IBEA) [67] and a simple indicator (Hypervolume) based evolutionary algorithm (SIBEA) [9] were proposed. In 2007, Beume et al. proposed the SMS-EMOA for getting a well-distributed set of Pareto optimal solutions where hypervolume is combined with nondominated sorting [7]. Hypervolume was also used in [4] for ranking the solutions in multi-objective optimization. In order to solve many objective optimization problems based on the performance indicator framework, Li et al. proposed the stochastic ranking-based multi-indicator Algorithm (SRA) in [28]. In [35], Pareto criterion and non-Pareto criterion are combined to utilize their strengths for MOPs.

Some traditional meta-heuristic algorihtms, such as particle swarm optimization (PSO), simulated annealing (SA), differential evolution (DE), ant colony optimization (ACO), artificial bee colony (ABC) algorithm have also been extended from single-objective optimization problem to MOPs [2], [6], [14], [25], [29], [46], [51], [57]. For example, Coello et al. [14] proposed the multi-objective PSO (MOPSO) algorithm. MOPSO uses an adaptive grid mechanism to preserve external population and introduces a new mutation strategy to increase the speed of convergence and maintain the diversity of solutions. However, the MOPSO does not deal with the global optimal particle effectively, making the algorithm easy to fall into local optimum. Zhang et. al introduced a competitive mechanism into MOPSO algorithm in order to reduce the dependant on the global or personal best position in the population [62]. Multi-objective optimization has also been used in different problem types, such as dynamic problems [22], [37], constrained problems [48], [58], and combinatorial problems [54]

In this paper, we propose a coordinate transformation based MOEA, MOEA/CT for short. In the proposed MOEA/CT, the coordinate system of the objective space is transformed according to each solution and the fitness of each objective function for a solution is re-evaluated, which is then regarded as the convergence information of each solution. Based on the convergence information, a new external elitist archive strategy is proceeded in MOEA/CT in order to find more effective solutions that help to accelerate the convergence process. For preventing the neighbor solutions from being selected in the external archive simultaneously and maintaining the spread of solutions, an $L_{p}$-norm based estimation of density is used with the Fractional distance instead of Euclidean distance for calculating the crowding distance of a solution.

The remainder of this paper is organized as follows. In Section $\Pi$, the backgrounds of MOPs and MOEAs are introduced. The details of the proposed MOEA/CT are presented in Section III Section IV studies the parameter setting for MOEA/CT, presents the experimental results on benchmark functions, and compares the MOEA/CT with the other six state-of-art MOEAs. Finally, the conclusions are drawn in Section $\mathrm{V}$

\section{BACKGROUNDS OF MOPS AND MOEAS}

\section{A. $M O P$}

Without loss of generality, an MOP can be formulated as follows:

$\min F(x)=\left(f_{1}(\vec{x}), f_{2}(\vec{x}), \ldots, f_{m}(\vec{x})\right)$, s.t. $\vec{x} \in S$ 
where $S \subset R^{n}$ is the decision (variable) space, $\vec{x}=$ $\left(x_{1}, x_{2}, x_{3}, \ldots, x_{n}\right) \in R^{n}$ is the vector of decision variables. $F: S \rightarrow R^{m}$ consists of $m$ real-valued objective functions $f_{1}(\vec{x}), f_{2}(\vec{x}), \cdots, f_{m}(\vec{x})$ and $R^{m}$ is called the objective space. In MOO, a solution $\vec{x}_{1}$ is said to dominate another solution $\vec{x}_{2}$, which is denoted as $\vec{x}_{1} \succ \vec{x}_{2}$ or $\vec{x}_{2} \prec \vec{x}_{1}$, if and only if the following conditions hold:

$$
\left\{\begin{array}{l}
\forall i \in 1,2, \cdots, m: f_{i}\left(\vec{x}_{1}\right) \geq f_{i}\left(\vec{x}_{2}\right) \\
\exists i \in 1,2, \cdots, m: f_{i}\left(\vec{x}_{1}\right)>f_{i}\left(\vec{x}_{2}\right) .
\end{array}\right.
$$

A solution $\vec{x}^{*}$ is said to be Pareto-optimal if and only if $\neg \exists \vec{x} \in R^{n}: \vec{x} \succ \vec{x}^{*}$. The set of all Pareto-optimal solutions is called Pareto set (PS) and the union of $F\left(\vec{x}^{*}\right)$ is called the Pareto front $(\mathrm{PF})$, that is

$$
P F \triangleq\left\{F\left(\vec{x}^{*}\right)=\left(f_{1}\left(\vec{x}^{*}\right), \cdots, f_{m}\left(\vec{x}^{*}\right)\right) \mid \vec{x}^{*} \in P S\right\} .
$$

\section{B. MOEA}

In [27], a unified model for MOEAs (UMMEA) with elitism is introduced where a specific MOEA can be regarded as an example of it. As formulated in UMMEA, two populations exist simultaneously, which are the 'normal population' $B$ and the 'elite population' $A$. At the beginning of UMMEA, the elite population and the initial population are initially generated and the parameter elitism intensity $p_{e}$ is also initialised. In the following iterative steps, the offspring population is generated from the previous offspring population and the elite population. The parameter $p_{e}$ is used to control the number of individuals in the elite population to be involved in the offspring population. The elite population updates according to the elitism strategy which refers to the use of an external archive to store the non-dominated individuals and its size is bounded. For evaluating the fitness of individuals, various strategies can be used by the users. The crossover and mutation operators are conducted for creating new offspring population.

\section{Multi-OBJECTIVE EVOLUTIONARY ALGORITHM BASED ON COORDINATE TRANSFORMATION (MOEA/CT)}

In this paper, a novel MOEA, termed as MOEA/CT, is presented by cooperating the proposed coordinate transformation (CT) strategy, the external archive update strategy, and the diversity maintenance strategy.

\section{A. Coordinate transformation strategy}

In general, an MOEA is hoped to obtain the non-dominated set of solutions as close as possible to or covering the $P F^{*}$. Therefore, in order to find more efficient non-dominated individuals, the CT strategy is designed in this paper to accelerate the convergence process and to quickly approximate the complete $P F^{*}$. Similar to the shift-based density estimation (SDE) method in [33] [29], where an individual's density is estimated by shifting other individuals in the population with regard to the individual in order to improve the distribution of population, in the CT strategy, an individual compares with each individual in the population in order to improve the convergence of the algorithm. In the CT strategy, the coordinate system of the objective space is transformed according to the position of each individual. That is, for each individual, its position is regarded as the new origin and then the other individuals are transformed according to the new origin. The distances of each individual to all the other individuals in the transformed coordinate system is summarised as the fitness of the individual.

Let $i, j$ be two individuals, the number of objectives is $m$, and the number of individuals in the population is $n$. The position of individual $i$ is set as the origin of the transformed coordinate system and the individual $j$ is then adjusted as

$q_{j(k)}^{\prime}=\left\{\begin{array}{cl}p_{i(k)}-q_{j(k)}, & \text { if } p_{i(k)}>q_{j(k)}, j \in 1,2, \ldots, n ; \\ 0, & \text { otherwise }, k \in 1,2, \ldots, m ;\end{array}\right.$

$$
d\left(p_{i}, q_{j}^{\prime}\right)=\sqrt{\sum_{k=1}^{m}\left(q_{j}^{\prime}(k)\right)^{2}},
$$

where $p_{i}(k)$ and $q_{j}(k)$ represent the fitness of the $k$ th objective of the individuals $i$ and $j$ respectively in the original coordinate system, $q_{j}^{\prime}(k)$ is the fitness of the $j$ th individual after the coordinate transformation. Then the summarised distances for individual $i$ can be calculated as

$$
D_{p_{i}}=\sum_{j=1}^{n-1} d\left(p_{i}, q_{j}^{\prime}\right) /(n-1),
$$

where $d\left(p_{i}, q_{j}^{\prime}\right)$ denotes the distance between the individuals $i$ and $j$ in the transformed coordinate system.

The pseudo code of the CT strategy is shown in Algorithm 1

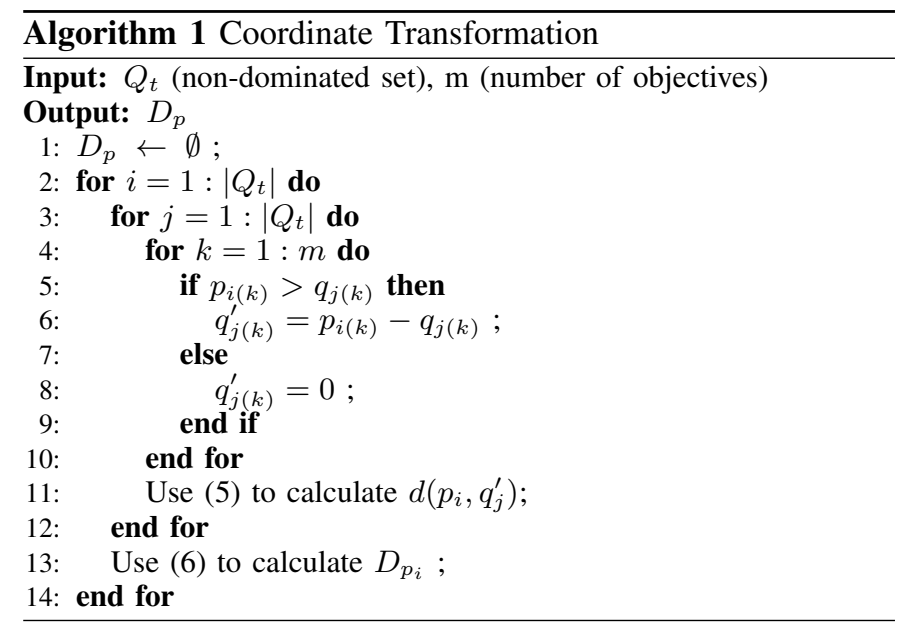

Here we take a bi-objective optimization problem as an example to illustrate the CT strategy. As shown in Fig 1, there are four non-dominated solutions $A(3,3), B(1,6), C(6,2)$, and $D(8,1)$ in the objective space. Let $A$ be the origin of the coordinate system. The solution $B(1,6)$ is better than the solution $A$ on the objective of $f_{1}$, then the solution $B$ is transformed along the direction of $f_{2}$ to get $B^{\prime}(-2,0)$. In the same way, the solutions $C$ and $D$ are transformed in the transformed coordinate system to get $C^{\prime}(0,-1)$ and $D^{\prime}(0,-2)$, respectively. According to Eqs. (4), (5), and (6), the distance fitness of $A$ is $D_{A}=1.67$

In Fig 2 (a) and (b), a concave PF is shown and the coordinate system is transformed according to the solution $A$ 
and $B$ respectively. The distance of $A$ to $B^{\prime}$ and $C^{\prime}$ and the distance of $B$ to $A^{\prime}$ and $C^{\prime}$ are shown in red in Fig 2 (a) and (b). It can be seen that the distance fitness of $A$ is less than that of $B$, which demonstrates better quality of the solution $A$ [64]. Fig 3 shows another instance where the PF is convex and the solution $A$ is better than the other two solutions $B$ and $C$ based on the CT strategy.

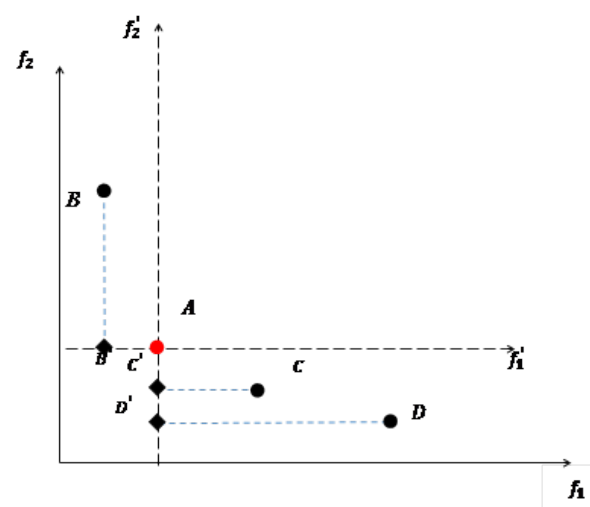

Fig. 1. An example of CT strategy

\section{B. External archive update strategy}

With the increasing of iterations, the number of nondominated solutions is increased exponentially, which will reduce the convergence speed and the accuracy of converging to the Pareto optimal front. Therefore, it is necessary to update the non-dominated solutions with a certain amount. Here, we use the external archive to preserve the non-dominated solutions during the evolutionary procedure with the proposed update strategy.

As described in Section [III-A, the distances between the individuals in the transformed coordinate system can reflect the quality of the solutions. In the proposed external archive update strategy, the fitness of the $i$ th individual defined by Eq. (6) is firstly normalized as:

$$
\gamma_{i}=D_{i}-M i n \_d_{i} / M a x \_d_{i}-M i n \_d_{i},
$$

where $M a x_{-} d_{i}$ and $M i n_{-} d_{i}$ are the maximum and minimum distance from the individual $i$ to the other individuals.

In order to evaluate the difference between the $i$ th individual and the others with more accuracy, we construct the following function:

$$
O_{i}=\left|\gamma_{i}^{2}-\left(\frac{\sum_{j=1}^{n}\left(D_{j}-M a x \_d_{j}\right)}{\sum_{j=1}^{n}\left(M a x \_d_{j}-M i n \_d_{j}\right)}\right)^{2}\right| .
$$

In order to converge to the Pareto optimal front more quickly, we rewrite Eq. 8 as

$$
O_{i}^{\prime}=\left(O_{i}\right)^{\frac{1}{\alpha}},
$$

where $1 / \alpha$ is used to search for the optimal objective value of the function in this degree and $\alpha$ indicates the number of objectives. With the increasing in the number of iterations, the number of non-dominated solutions will continue to increase, making the solution set become larger, which results in a decrease in the efficiency of the algorithm. In order to control the number of non-dominated solutions, on the basis of Eq. 9 we introduce a linearly decreasing factor $g_{\max } / g$, where $g$ means the current iteration number and $g_{\max }$ means the total number of iterations. Hence, the final discrimination function is as follows:

$$
\mathrm{O}_{i}^{\prime \prime}=O_{i}^{\prime} \cdot \frac{g_{\max }}{g}
$$

Finally, we choose individual $i$ with $\gamma_{i}<O_{i}^{\prime \prime}$ as the basis access to the external archive. The sensitivity of $\alpha$ on the convergence of the algorithm will be studied in detail in Section IV] From the formulation of Eq. 10, it can be found that the function not only considers the population size but also the distance from the $i$ th individual to the other individuals. The function can dynamically adjust along with the iterations, which can keep the optimal individuals as much as possible.

\section{Diversity maintenance strategy}

In existing MOEAs, the crowding distance is usually used to guide the selection procedure for keeping the diversity and getting a uniformly distributed PF. The Euclidean $L_{2}$-norm distance and Mahalanobis distance are the common methods to calculate the crowding distance [32], [38], [40]. However, these distance measurements cannot accurately reflect the degree of crowding among the individuals when the number of objectives is increasing [1]. Meanwhile, the crowding distance among all the individuals should be calculated and large deviations may occur when two individuals are far away from each other. In [26], [47], it is pointed out that an MOEA with the Fractional distance ( $L_{p}$-norm) is more efficient when dealing with high dimensional problems compared to that with the $L_{2}$-norm distance. Aggarwal et al. concluded that a higher contrast between the nearest and farthest neighbors can be obtained with a smaller $p$ in the Fractional distance [1]. Therefore, in this paper we use the Fractional distance in the proposed MOEA/CT to measure the crowding distance and set $p=1 / m$ ( $m$ is the number of objectives) as that in [47], the formula is shown as follows:

$$
L_{p}(\beta, \theta)=\sum_{i=1}^{m}\left(\left\|\beta^{i}-\theta^{i}\right\|^{p}\right)^{1 / p} .
$$

When the number of non-dominated solutions is larger than the population size, the solutions with the maximum and minimum fitness values are firstly selected, which helps to distribute the individuals more uniformly. Then, the crowding distance is calculated based on the $L_{p}$-norm distance. At last, the individuals will be selected according to the distances. The pseudo code of the diversity maintenance strategy is shown in Algorithm 2 The pseudo code of MOEA/CT is shown in Algorithm 3

\section{Computational complexity of MOEA/CT}

The computational complexity of MOEA/CT is derived from the coordinate transformation, non-dominated sorting and 


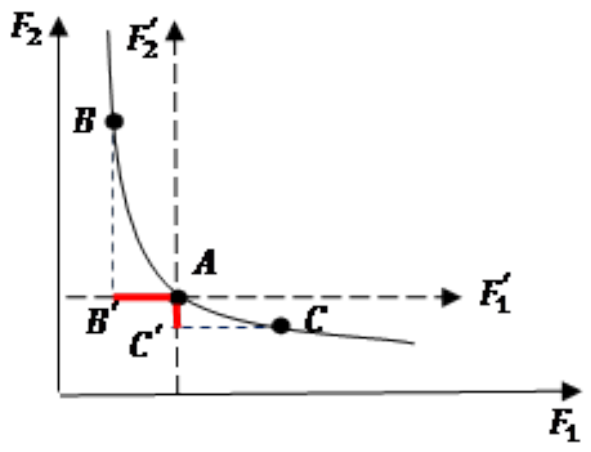

(a)

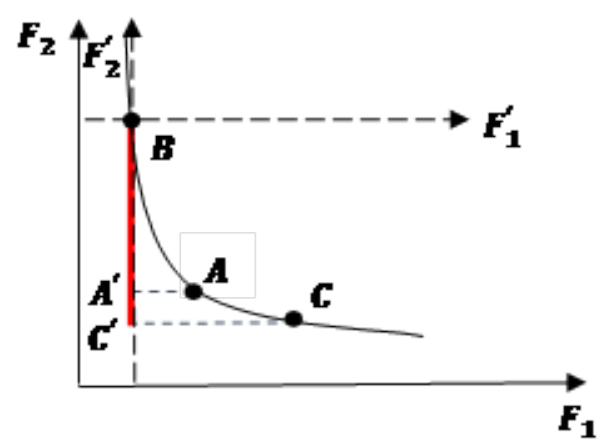

(b)

Fig. 2. Example of CT strategy with a concave PF; (a) $A$ is the origin; (b) $B$ is the origin

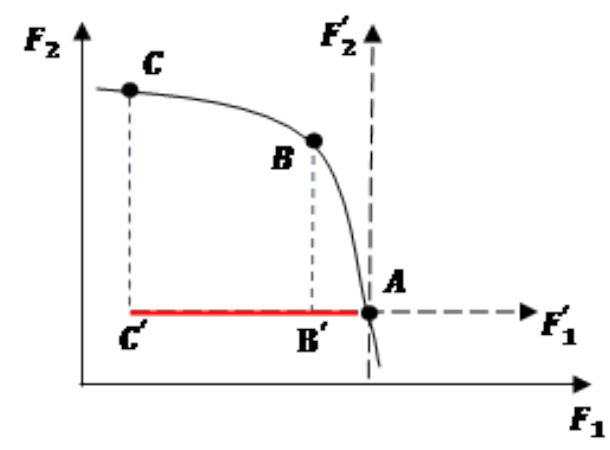

(a)

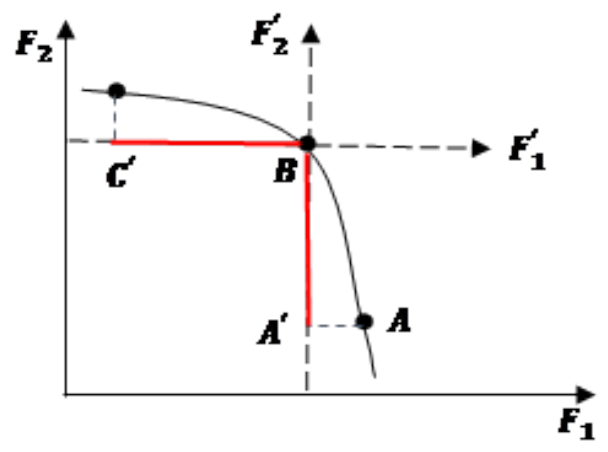

(b)

Fig. 3. Example of CT strategy with a convex PF; (a) $A$ is the origin; (b) $B$ is the origin

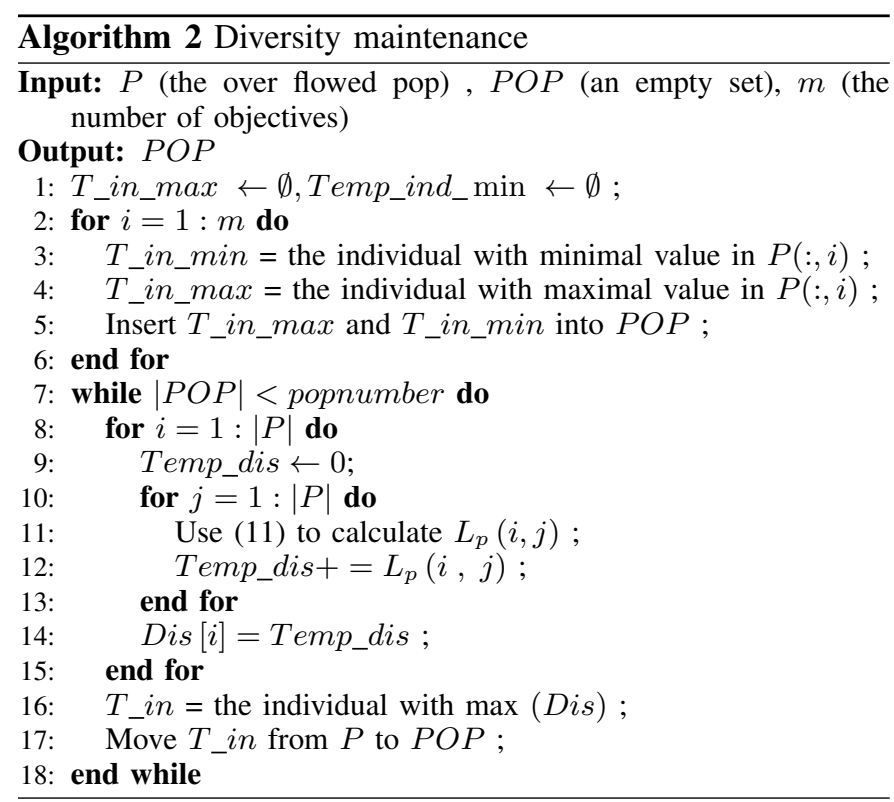

the calculation of crowding distances. For the MOP with $m$ objectives and MOEA/CT with the population size of $N$, the coordinate transformation costs $O\left((m N)^{2}\right)$, the non-dominated sorting costs $O\left(N \log ^{M-2} N\right)$ [26], and the calculation of crowding distances costs $O\left(m N^{2}\right)$. Hence, the total complex-

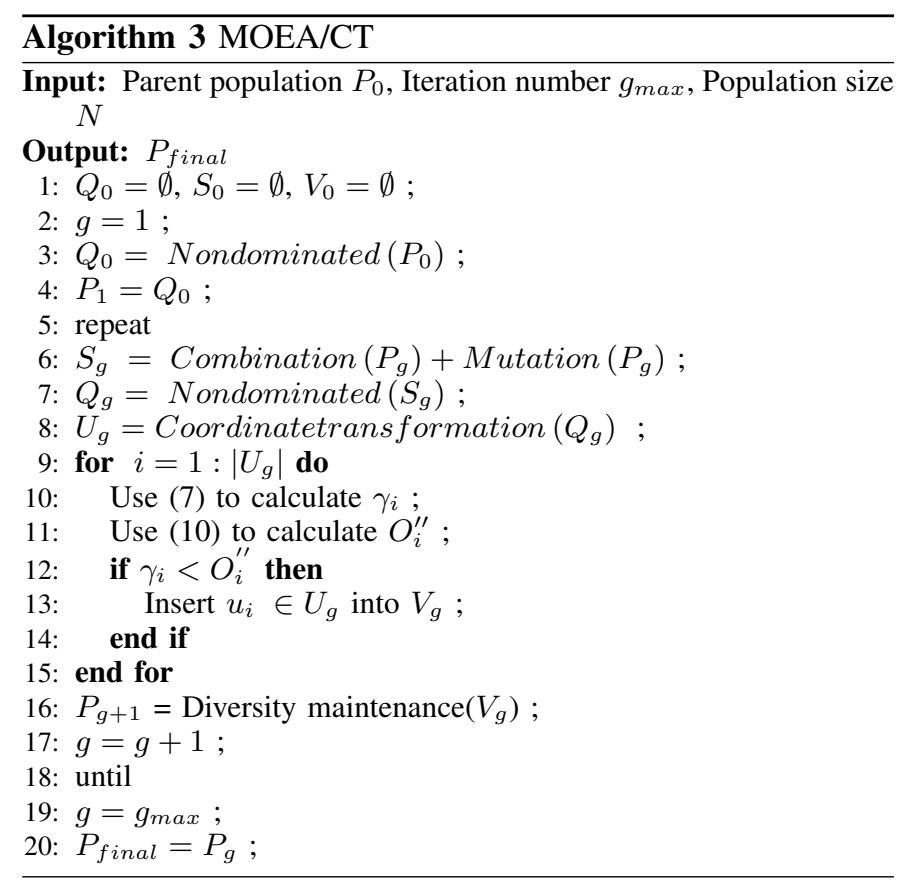

ity of MOEA/CT is $\max \left(O\left(N \log ^{M-2} N\right), O\left(m N^{2}\right)\right)$. 


\section{EXPERIMENTAL RESULTS}

\section{A. Experimental setup}

1) Test problems: Thirteen different types of test problems are selected to evaluate the performance of MOEA/CT, including ZDT1, ZDT2, ZDT3, ZDT6 functions, Kursawe function [17], and Fonseca function [42] with two objectives [18], DTLZ1, DTLZ2, DTLZ3, DTLZ4 [21], WFG1, WFG2, and WFG3 [23] functions with three objectives. The search ranges, dimensions, and maximum iterations of the thirteen test problems are listed in Table I].

TABLE I

TEST PROBLEMS

\begin{tabular}{rcc}
\hline \multicolumn{1}{c}{ Problems } & Search Ranges & Maximum Iterations \\
\hline ZDT1/ZDT2/ZDT3 & {$[0,1]^{30}$} & 250 \\
ZDT6 & {$[0,1]^{10}$} & 250 \\
Kursawe & {$[-5,5]^{3}$} & 100 \\
Fonseca & {$[-4,4]^{3}$} & 100 \\
DTLZ1 & {$[0,1]^{7}$} & 150 \\
DTLZ2 & {$[0,1]^{12}$} & 100 \\
DTLZ3, DTLZ4 & {$[0,1]^{12}$} & 250 \\
WFG1/WFG2/WFG3 & {$[0,40]^{20}$} & 300 \\
\hline
\end{tabular}

2) Performance Metrics: In order to evaluate the convergence performance and distribution performance of the algorithms, we use the Generational Distance (GD), Inverted Generational Distance (IGD), Spacing (SP), convergence indicator $(\gamma)$ and Maximum Spread $(M S)$ as the performance metrics. Let $P^{*}$ be a set of known uniformly distributed solutions along $\mathrm{PF}$ in the objective space and $P$ be an approximation to PF achieved by the algorithm.

a) GD: GD [45] describes the distance between $P$ and $P^{*}$, which is defined as

$$
G D=\sqrt{\sum_{x \in P} d_{i}^{2}} /|P|,
$$

where $d_{i}$ represents the minimum Euclidean distance between the $i$ th non-dominated solution in $\mathrm{P}$ and the solutions in PF. A smaller value of GD means a better convergence to PF.

b) IGD: IGD [66] is a comprehensive indicator to measure the convergence and diversity simultaneously of $P$ if $\left|P^{*}\right|$ is is large enough. The IGD between $P$ and $P^{*}$ is defined as follows:

$$
\operatorname{IGD}\left(P^{*}, P\right)=\sum_{x \in P^{*}} d(x, P) /\left|P^{*}\right|,
$$

where $d(x, P)$ is the Euclidean distance between the solution $x$ and the closest solution in the set $P$ from $x$. A smaller value of IGD indicates a better diversity and convergence to PF.

c) $\gamma: \gamma$ is used to measure the similarity of the nondominated solution set $P$ achieved by the algorithm approximating to the PF [20], which is defined as

$$
\begin{array}{r}
\gamma=\sum_{i=1}^{|P F|} d_{i} /|P F|, \\
d_{i}=\min _{1<j<|P F|} \sqrt{\sum_{k=1}^{m}\left(\frac{f_{k}^{i}(\vec{x})-f_{k}^{j}(\vec{x})}{f_{k}^{\text {max }}(\vec{x})-f_{k}^{\text {min }}(\vec{x})}\right)^{2}},
\end{array}
$$

where $f_{k}^{\max }$ and $f_{k}^{\text {min }}$ are the maximum and minimum values of the $k$ th objective of all solutions in PF, $m$ is the number of objectives. A smaller value of $\gamma$ indicates a better approximation to $\mathrm{PF}$.

d) $M S: M S$ [36] is used to measure the range of coverage of the solved Pareto optimal set to the true Pareto optimal front. The formulation of $M S$ is

$M S=\sqrt{\frac{1}{m} \sum_{i=1}^{m}\left[\frac{\min \left(f_{i}^{\max }, F_{i}^{\max }\right)-\max \left(f_{i}^{\min }, F_{i}^{\min }\right)}{F_{i}^{\max }-F_{i}^{\min }}\right]^{2}}$,

where $m$ is the number of objectives, $f_{k}^{\max }$ and $f_{k}^{\min }$ are the maximum and minimum fitness values of the $k$ th objective among all the solutions in $P, F_{i}^{\max }$ and $F_{i}^{\text {min }}$ are the maximum and minimum values of the $i$ th objective of all the solutions in $P^{*}$. The closer the value of $M S$ to 1 indicates the wider the range of distribution.

e) $S P$ : The spacing metric [16] indicates the uniformity of the solutions, which is to calculate the variance of the Pareto-optimal solutions achieved by the algorithm, that is,

$$
\begin{array}{r}
S P=\sqrt{\frac{1}{n-1} \sum_{i=1}^{n}\left(d_{i}-\bar{d}\right)^{2},} \\
d_{i}=\min _{j}\left(\left|f_{1}^{i}(\vec{x})-f_{1}^{j}(\vec{x})\right|+\cdots+f_{m}^{i}(\vec{x})-f_{m}^{j}(\vec{x})\right), \\
\bar{d}=\sum_{i=1}^{n} d_{i} / n,
\end{array}
$$

where $n$ is the number of Pareto-optimal solutions in $P, i, j=$ $1,2, \cdots, n, f_{k}^{i}(\vec{x})$ denotes the $k$ th objective function value of the $i$ th solution in $P$. The smaller the value of $S P$ means the more uniform distribution of the obtained Pareto-optimal solutions.

\section{B. Performance comparison}

In order to completely evaluate the performance of MOEA/CT, NSGA-III [15], SPEA2+SDE [33], MOEA/DD [30], Two_arch2 [47], ssNSGAII_ENLU [31], MOEAD_DRA_ASTM [50], SPEA2+DECOM [63] and CMOPSO [62] are taken to compare with MOEA/CT. The source codes of Two_arch2, SPEA2+SDE, SPEA2+DECOM, MOEAD_DRA_ASTM and ssNSGAII_ENLU are downloaded from the websites. The other three algorithms are implemented in the PlatEMO [43]. The specific parameter settings for each algorithm are chosen according to the recommended values in the original literature. In this paper, we use the SBX crossover operator and the polynomial mutation operator in the proposed algorithm [15]. For all the experiments, the population size is 100 . There are four parts in the experiments. The first part is to investigate the sensitivity to the parameter $\alpha$. The purpose is to find a suitable value for $\alpha$ with respect to the num of objectives. The second one is to compare the proposed CT scheme with SDE scheme in order to find the performance difference. The third one and the fourth one are to compare MOEA/CT with the other eight MOEAs on bi-objective and tri-objective problems respectively. The aim is to illustrate the ability of MOEA/CT in MOPs. 
1) Sensitivity analysis to the parameter $\alpha$ : The parameter $\alpha$ in MOEA/CT is used to control the convergence performance of the algorithm, which should be specified by the user. Here, the performance sensitivity of MOEA/CT to $\alpha$ with the values of $1,2,3,5,10,20$ will be studied on the bi-objective function ZDT1 and tri-objecitve function DTLZ1. The choice of ZDT1 and DTLZ1 is not special and they are only selected to represent the bi-objective problem and tri-objective problem.

As shown in Fig 4 (a), with the increasing of the iterations, the convergence indicator $\gamma$ is decreasing. MOEA/CT with $\alpha=$ 2 gets the smallest $\gamma$ value, which shows that the convergence rate of the algorithm is the fastest in this situation. We can also find that each convergence curve in Fig 4 fluctuates in the beginning, which is due to the random selection of individuals in the initial stage.

Fig 4 (b) gives the overall trend of the convergence indicator $\gamma$, which appears to decrease with the increase of iterations, but the curves fluctuate greatly than that in Fig 4 (a). This is due to the fact that with the increasing of the number of objects, a small change in an individual will cause large deviation in the fitness value. The value of $\gamma$ is relatively stable with $\alpha$ $=3$ compared to the other instances. When the $\alpha$ value is too large, such as $\alpha=10$, most of the individuals are removed and then new random individuals are generated which reduces the convergence speed. On the contrary, when the $\alpha$ value is too small, such as $\alpha=1$, too much inferior solutions are retained which results in the $\gamma$ value keeping unchanged for a long time. When $\alpha$ is 2 and 5, similar results can be found, that is, between the 50th and 120th iterations convergence the rate is fast and around the 150th iteration the convergence curve fluctuates much more, which may lead to the premature convergence.

Therefore, based on the above analysis, we set $\alpha=2$ when MOEA/CT is used to solve bi-objective functions and $\alpha=3$ for the tri-objective problems in this paper.

TABLE II

COMPARISONS BETWEEN MOEA/CT AND MOEA/SDE

\begin{tabular}{|c|c|c|c|c|}
\hline \multirow[b]{2}{*}{ Indicator } & MOEA/CT & MOEA/SDE & MOEA/CT & MOEA/SDE \\
\hline & \multicolumn{2}{|c|}{ ZDT2 } & \multicolumn{2}{|c|}{ ZDT6 } \\
\hline \multirow{2}{*}{ GD } & $8.20 \mathrm{E}-05$ & $8.75 \mathrm{E}-05$ & $1.40 \mathrm{E}-04$ & $1.46 \mathrm{E}-04$ \\
\hline & $1.89 \mathrm{E}-06$ & 2.07E-05 & 8.73E-06 & 1.33E-05 \\
\hline \multirow{2}{*}{ SP } & $6.16 \mathrm{E}-03$ & $6.45 \mathrm{E}-03$ & $4.40 \mathrm{E}-03$ & 4.46E-03 \\
\hline & $1.94 \mathrm{E}-04$ & $1.52 \mathrm{E}-03$ & 2.63E-04 & $2.48 \mathrm{E}-04$ \\
\hline \multirow[b]{2}{*}{$\gamma$} & 7.78E-04 & $9.82 \mathrm{E}+04$ & $1.37 \mathrm{E}-03$ & $1.42 \mathrm{E}-02$ \\
\hline & $1.56 \mathrm{E}-05$ & $4.39 \mathrm{E}+05$ & $8.51 \mathrm{E}-05$ & $1.31 \mathrm{E}-03$ \\
\hline \multirow{3}{*}{ MS } & $1.00 \mathrm{E}+00$ & $9.50 \mathrm{E}-01$ & $1.00 \mathrm{E}+00$ & $1.00 \mathrm{E}+00$ \\
\hline & $2.51 \mathrm{E}-06$ & $2.24 \mathrm{E}-01$ & $0.00 \mathrm{E}+00$ & $0.00 \mathrm{E}+00$ \\
\hline & \multicolumn{2}{|c|}{ DTLZ2 } & \multicolumn{2}{|c|}{ DTLZ3 } \\
\hline \multirow{2}{*}{ GD } & 6.56E-04 & $8.02 \mathrm{E}-04$ & 6.12E-04 & $6.58 \mathrm{E}-04$ \\
\hline & $1.27 \mathrm{E}-04$ & 3.74E-04 & 1.16E-04 & $1.20 \mathrm{E}-04$ \\
\hline \multirow{2}{*}{ SP } & $3.84 \mathrm{E}-02$ & 3.67E-02 & $3.89 \mathrm{E}-02$ & $3.76 \mathrm{E}-02$ \\
\hline & $3.39 \mathrm{E}-03$ & 3.05E-03 & $3.19 \mathrm{E}-03$ & $2.62 \mathrm{E}-03$ \\
\hline \multirow[b]{2}{*}{$\gamma$} & 4.48E-03 & $5.67 \mathrm{E}-02$ & 4.18E-03 & $5.05 \mathrm{E}-02$ \\
\hline & 4.79E-04 & $8.11 \mathrm{E}-03$ & 4.29E-04 & $6.12 \mathrm{E}-03$ \\
\hline \multirow{2}{*}{ IGD } & $5.39 \mathrm{E}-02$ & $5.38 \mathrm{E}-02$ & 5.19E-02 & $5.39 \mathrm{E}-02$ \\
\hline & 7.42E-04 & 5.98E-04 & $6.22 \mathrm{E}-04$ & 4.67E-04 \\
\hline
\end{tabular}

2) Comparison experiments between $C T$ and SDE: Since the shift scheme for individuals regarding their convergence comparison in SDE has the similar idea of the proposed CT scheme in this paper, we carry out the comparison between SDE and $\mathrm{CT}$ in order to make clear the performance difference. For fair comparison, SDE is employed in MOEA (MOEA/SDE), which is the same as CT with MOEA. MOEA/SDE and MOEA/CT are used to solve the functions of ZDT2, ZDT6, DTLZ2, and DTLZ3. The parameter setting from MOEA/SDE is the same as those for MOEA/CT. The experimental results over 30 independent runs are shown in Table III. It is obviously that MOEA/CT gets the best performance on both bi-objective functions regarding the four performance metrics. For tri-objective functions DTLZ2 and DTLZ3, MOEA/SDE shows better performance than MOEA/CT on the results of SP and MOEA/CT outperforms MOEA/SDE on the results of GD and $\gamma$. From the overall results of the four instances, the CT scheme is more effective than the SDE scheme.

3) Comparison experiments on bi-objective problems: For each compared algorithm on each test function, 30 independent runs are performed. The experimental results of mean values and standard deviations of four performance metrics obtained by nine algorithms on six test functions are given in Table III. The best value of each performance metric on each test function among the nine algorithms is shown in bold. The Wilconxon rank sum test is used at a significance level of 0.05. The symbols ' + ', '-', and ' $=$ ' in Table III indicate that the statistical test result is significantly better, significantly worse and statistically similar to that solved by MOEA/CT, respectively. The term ' $b / w / e$ ' at the bottom of Table III indicates the number of functions that MOEA/CT performs significantly better than, significantly worse than, and statistically similar to the compared algorithm; and ' $\mathrm{gm}$ ' is the difference between the term ' $b$ ' and ' $w$ ' in order to show the overall comparison between MOEA/CT and the compared algorithm.

The non-dominated solution set of ZDT1 is convex in the objective space. From Table III it is clear that all the algorithms have a good GD value where CMOPSO shows the best performance. SPEA2+DECOM and ssNSGAII_ENLU get the best value on the metrics of $\gamma$ and SP respectively. As MS value is concerned, CMOPSO, SPEA2+DECOM, and ssNSGAII_ENLU have similar good performance followed by MOEA/CT, SPEA2+SDE, Two_arch2, and MOEAD_DRA_ASTM. NSGA-III got the worst MS value.

The non-dominated solution sets of ZDT2 and Fonseca in the objective space are both non-convex.For ZDT2, MOEA/CT shows very good performance regarding almost all the four performance indicators except on SP, that is, the obtained non-dominated solutions distribute uniformly, close to the real front, and coverage widely as the true PF. The MS values obtained by MOEA/CT, SPEA2+SDE, ssNSGAII_ENLU, SPEA2+DECOM, and CMOPSO are almost the same. For Fonseca, MOEAD_DRA_ASTM runs the first on GD value and it is slightly better than that of MOEA/CT.

The ZDT3 function contains $21^{9}$ local PF. The solution set of the Kursawe function is nonconvex and discontinuous. Both functions are suitable for testing the performance of algorithms for solving multi-modal functions. For ZDT3, MOEA/CT obtains the best values on three metrics which are GD, $\gamma$, and MS and Two_arch2 shows the best value on SP. For Kursawe, MOEA/CT and Two_arch2 get similar values on all the four 
TABLE III

PERFORMANCE COMPARISONS OF MOEA/CT to DIFFERENT MOEAs WITH RESPECT TO THE AVERAGE GD, SP, $\gamma$, AND MS VALUES ON BI-OBJECTIVE PROBLEMS. THE BEST AVERAGE VALUES OF DIFFERENT METRICS AMONG THE NINE ALGORITHMS FOR EACH INSTANCE IS HIGHLIGHTED IN BOLD

\begin{tabular}{|c|c|c|c|c|c|c|c|c|c|c|}
\hline Function & Indicator & MOEA/CT & NSGA-III & $\begin{array}{c}\text { SPEA2+ } \\
\text { SDE }\end{array}$ & MOEA/DD & Two_arch2 & $\begin{array}{c}\text { ssNSGAII_ } \\
\text { ENLU }\end{array}$ & $\begin{array}{l}\text { MOEAD_ } \\
\text { DRA_- }_{\text {ASTM }}\end{array}$ & $\begin{array}{l}\text { SPEA2+ } \\
\text { DECOM }\end{array}$ & CMOPSO \\
\hline \multirow{8}{*}{ ZDT1 } & \multirow{2}{*}{ GD } & $3.01 \mathrm{E}-04$ & $1.82 \mathrm{E}-04^{-}$ & $1.25 \mathrm{E}-04^{-}$ & $1.12 \mathrm{E}-03^{+}$ & $2.57 \mathrm{E}-03^{+}$ & $2.42 \mathrm{E}-04^{-}$ & $1.56 \mathrm{E}-04^{-}$ & $1.04 \mathrm{E}-04^{-}$ & $4.12 \mathrm{E}-05^{-}$ \\
\hline & & 3.35E-06 & $3.50 \mathrm{E}-05$ & $4.53 \mathrm{E}-05$ & 7.10E-04 & $2.59 \mathrm{E}-05$ & $1.10 \mathrm{E}-05$ & $1.31 \mathrm{E}-05$ & $3.56 \mathrm{E}-05$ & $1.70 \mathrm{E}-05$ \\
\hline & \multirow{2}{*}{ SP } & $6.78 \mathrm{E}-03$ & $1.94 \mathrm{E}-02^{+}$ & $7.12 \mathrm{E}-03^{+}$ & $1.35 \mathrm{E}-02^{+}$ & $7.41 \mathrm{E}-03^{+}$ & $1.65 \mathrm{E}-03^{-}$ & $1.00 \mathrm{E}-02^{+}$ & $1.01 \mathrm{E}-02^{+}$ & $2.96 \mathrm{E}-03^{-}$ \\
\hline & & $2.01 \mathrm{E}-04$ & $7.25 \mathrm{E}-03$ & $1.43 \mathrm{E}-03$ & $7.66 \mathrm{E}-03$ & $4.24 \mathrm{E}-04$ & 2.51E-04 & $1.96 \mathrm{E}-04$ & $1.55 \mathrm{E}-03$ & $2.37 \mathrm{E}-04$ \\
\hline & \multirow[b]{2}{*}{$\gamma$} & $1.51 \mathrm{E}-03$ & $1.52 \mathrm{E}-03=$ & $8.58 \mathrm{E}-03^{+}$ & $1.70 \mathrm{E}-01^{+}$ & $5.14 \mathrm{E}-01^{+}$ & $1.19 \mathrm{E}-03^{-}$ & $1.47 \mathrm{E}-03^{-}$ & $7.61 \mathrm{E}-04^{-}$ & $1.61 \mathrm{E}-03^{+}$ \\
\hline & & $2.50 \mathrm{E}-04$ & $6.28 \mathrm{E}-04$ & $7.56 \mathrm{E}-04$ & 3.96E-02 & 7.34E-04 & $9.05 \mathrm{E}-05$ & $1.34 \mathrm{E}-04$ & $6.81 \mathrm{E}-05$ & $6.41 \mathrm{E}-04$ \\
\hline & \multirow{2}{*}{ MS } & $9.99 \mathrm{E}-01$ & $8.43 \mathrm{E}-01^{+}$ & $9.80 \mathrm{E}-01^{+}$ & $8.89 \mathrm{E}-01^{+}$ & $9.98 \mathrm{E}-01^{+}$ & $1.00 \mathrm{E}+00^{-}$ & $9.99 \mathrm{E}-01^{-}$ & $1.00 \mathrm{E}+00^{-}$ & $1.00 \mathrm{E}+00^{-}$ \\
\hline & & $2.10 \mathrm{E}-04$ & $1.04 \mathrm{E}-01$ & 7.53E-03 & 4.31E-02 & $2.25 \mathrm{E}-04$ & 1.34E-04 & $3.76 \mathrm{E}-04$ & 1.68E-04 & 1.44E-04 \\
\hline \multirow{8}{*}{ ZDT2 } & \multirow{2}{*}{ GD } & $9.20 \mathrm{E}-05$ & $1.65 \mathrm{E}-04^{+}$ & $9.65 \mathrm{E}-05^{+}$ & $5.09 \mathrm{E}-03^{+}$ & $9.21 \mathrm{E}-05^{=}$ & $1.17 \mathrm{E}-04^{+}$ & $2.06 \mathrm{E}-04^{+}$ & $9.62 \mathrm{E}-05^{+}$ & $9.61 \mathrm{E}-05^{+}$ \\
\hline & & $1.89 \mathrm{E}-06$ & $3.24 \mathrm{E}-05$ & $8.61 \mathrm{E}-06$ & $4.48 \mathrm{E}-03$ & $3.24 \mathrm{E}-05$ & $6.59 \mathrm{E}-05$ & $3.04 \mathrm{E}-05$ & $2.22 \mathrm{E}-06$ & $3.30 \mathrm{E}-05$ \\
\hline & \multirow[b]{2}{*}{ SP } & $6.76 \mathrm{E}-03$ & $6.04 \mathrm{E}-02^{+}$ & $1.03 \mathrm{E}-02^{+}$ & $4.61 \mathrm{E}-02^{+}$ & $1.91 \mathrm{E}-02^{+}$ & $1.71 \mathrm{E}-03^{-}$ & $5.38 \mathrm{E}-03^{-}$ & $6.07 \mathrm{E}-03^{-}$ & $3.13 \mathrm{E}-03^{-}$ \\
\hline & & $1.94 \mathrm{E}-04$ & $8.58 \mathrm{E}-03$ & $1.24 \mathrm{E}-03$ & $3.90 \mathrm{E}-02$ & $8.58 \mathrm{E}-03$ & 3.31E-04 & $3.56 \mathrm{E}-04$ & $7.41 \mathrm{E}-04$ & $4.01 \mathrm{E}-04$ \\
\hline & \multirow[b]{2}{*}{$\gamma$} & 7.78E-04 & $1.03 \mathrm{E}-03^{+}$ & $8.03 \mathrm{E}-04^{+}$ & 4.47E-01+ & $1.30 \mathrm{E}-03^{+}$ & $9.21 \mathrm{E}-04^{+}$ & $1.93 \mathrm{E}-03^{+}$ & $7.91 \mathrm{E}-04^{+}$ & $8.16 \mathrm{E}-04^{+}$ \\
\hline & & $1.56 \mathrm{E}-05$ & $5.35 \mathrm{E}-04$ & $6.57 \mathrm{E}-05$ & 2.53E-01 & $5.35 \mathrm{E}-04$ & $1.02 \mathrm{E}-04$ & $2.63 \mathrm{E}-04$ & $1.77 \mathrm{E}-05$ & $6.34 \mathrm{E}-04$ \\
\hline & \multirow{2}{*}{ MS } & $1.00 \mathrm{E}+00$ & $9.16 \mathrm{E}-01^{+}$ & $1.00 \mathrm{E}+00=$ & $6.86 \mathrm{E}-01^{+}$ & $9.99 \mathrm{E}-01^{+}$ & $1.00 \mathrm{E}+00^{+}$ & $9.99 \mathrm{E}-01^{+}$ & $1.00 \mathrm{E}+00^{+}$ & $1.00 \mathrm{E}+00^{+}$ \\
\hline & & $2.51 \mathrm{E}-06$ & $5.56 \mathrm{E}-01$ & $4.94 \mathrm{E}-16$ & $1.32 \mathrm{E}-01$ & $0.00 \mathrm{E}+00$ & 9.01E-05 & $2.09 \mathrm{E}-04$ & $1.86 \mathrm{E}-05$ & $1.85 \mathrm{E}-04$ \\
\hline \multirow{8}{*}{ ZDT3 } & \multirow{2}{*}{ GD } & 6.73E-04 & $2.03 \mathrm{E}-03^{+}$ & $6.76 \mathrm{E}-04^{+}$ & $4.53 \mathrm{E}-03^{+}$ & $7.00 \mathrm{E}-04^{+}$ & $6.85 \mathrm{E}-04^{+}$ & $5.97 \mathrm{E}-03^{+}$ & $6.89 \mathrm{E}-04^{+}$ & $6.94 \mathrm{E}-04^{+}$ \\
\hline & & 3.71E-06 & $3.05 \mathrm{E}-03$ & $4.00 \mathrm{E}-05$ & $5.13 \mathrm{E}-04$ & $9.55 \mathrm{E}-06$ & $4.83 \mathrm{E}-05$ & $2.50 \mathrm{E}-04$ & $3.49 \mathrm{E}-05$ & $5.96 \mathrm{E}-06$ \\
\hline & \multirow{2}{*}{ SP } & $5.74 \mathrm{E}-03$ & $2.78 \mathrm{E}-02^{+}$ & $1.12 \mathrm{E}-02^{+}$ & $1.01 \mathrm{E}-01^{+}$ & $3.79 \mathrm{E}-03^{-}$ & $2.86 \mathrm{E}-03^{-}$ & $1.28 \mathrm{E}-02^{+}$ & $1.38 \mathrm{E}-02^{+}$ & $4.17 \mathrm{E}-03^{-}$ \\
\hline & & $1.21 \mathrm{E}-04$ & $9.46 \mathrm{E}-03$ & $1.24 \mathrm{E}-03$ & 2.87E-02 & $4.00 \mathrm{E}-04$ & $5.13 \mathrm{E}-04$ & $9.12 \mathrm{E}-04$ & $1.54 \mathrm{E}-03$ & $3.96 \mathrm{E}-04$ \\
\hline & \multirow[b]{2}{*}{$\gamma$} & 5.74E-03 & $6.58 \mathrm{E}-03^{+}$ & $6.13 \mathrm{E}-03^{+}$ & $1.36 \mathrm{E}-01^{+}$ & $1.51 \mathrm{E}-02^{+}$ & $6.71 \mathrm{E}-03^{+}$ & $2.17 \mathrm{E}-02^{+}$ & $6.50 \mathrm{E}-03^{+}$ & $8.89 \mathrm{E}-03^{+}$ \\
\hline & & 1.21E-04 & $4.78 \mathrm{E}-03$ & $1.76 \mathrm{E}-04$ & $3.95 \mathrm{E}-02$ & $5.41 \mathrm{E}-05$ & $1.71 \mathrm{E}-04$ & $5.92 \mathrm{E}-04$ & $1.28 \mathrm{E}-04$ & $3.15 \mathrm{E}-04$ \\
\hline & \multirow{2}{*}{ MS } & $1.00 \mathrm{E}+00$ & $9.07 \mathrm{E}-01^{+}$ & $9.94 \mathrm{E}-01^{+}$ & $8.81 \mathrm{E}-01^{+}$ & $9.99 \mathrm{E}-01^{+}$ & $9.89 \mathrm{E}-01^{+}$ & $9.89 \mathrm{E}-01^{+}$ & $9.89 \mathrm{E}-01^{+}$ & $9.17 \mathrm{E}-01^{+}$ \\
\hline & & $6.18 \mathrm{E}-06$ & $9.39 \mathrm{E}-02$ & $2.75 \mathrm{E}-03$ & 7.08E-02 & $1.78 \mathrm{E}-04$ & $3.35 \mathrm{E}-02$ & $3.34 \mathrm{E}-02$ & $3.31 \mathrm{E}-02$ & $1.35 \mathrm{E}-01$ \\
\hline \multirow{8}{*}{ ZDT6 } & \multirow{2}{*}{ GD } & 1.40E-04 & $2.30 \mathrm{E}-03^{+}$ & $1.47 \mathrm{E}-04^{+}$ & $1.63 \mathrm{E}-01^{+}$ & $1.68 \mathrm{E}-04^{+}$ & $4.03 \mathrm{E}-04^{+}$ & $8.42 \mathrm{E}-04^{+}$ & $1.68 \mathrm{E}-04^{+}$ & $1.17 \mathrm{E}-02^{+}$ \\
\hline & & 8.73E-06 & 7.33E-03 & $1.11 \mathrm{E}-05$ & 7.64E-03 & $9.35 \mathrm{E}-06$ & $4.92 \mathrm{E}-05$ & $1.02 \mathrm{E}-04$ & $6.49 \mathrm{E}-06$ & $1.25 \mathrm{E}-02$ \\
\hline & SP & $4.40 \mathrm{E}-03$ & $3.11 \mathrm{E}-02^{+}$ & $4.23 \mathrm{E}-\mathrm{O3}^{-}$ & $2.89 \mathrm{E}-01^{+}$ & $4.43 \mathrm{E}-03^{+}$ & $2.03 \mathrm{E}-03^{-}$ & $4.07 \mathrm{E}-03^{-}$ & $4.85 \mathrm{E}-03^{+}$ & $1.08 \mathrm{E}-01^{+}$ \\
\hline & $\mathrm{SP}$ & 2.63E-04 & $3.85 \mathrm{E}-02$ & $3.99 \mathrm{E}-04$ & $8.22 \mathrm{E}-02$ & $2.41 \mathrm{E}-04$ & 3.33E-04 & $6.95 \mathrm{E}-04$ & $1.03 \mathrm{E}-03$ & $1.18 \mathrm{E}-01$ \\
\hline & & 1.37E-03 & $5.41 \mathrm{E}-03^{+}$ & $1.38 \mathrm{E}-03^{+}$ & $1.97 \mathrm{E}-01^{+}$ & $1.41 \mathrm{E}-03^{+}$ & 4.94E-03+ & $1.03 \mathrm{E}-02^{+}$ & $2.04 \mathrm{E}-03^{+}$ & $1.93 \mathrm{E}-02^{+}$ \\
\hline & $\gamma$ & $8.51 E-05$ & $3.18 \mathrm{E}-03$ & $9.74 \mathrm{E}-05$ & $1.03 \mathrm{E}-01$ & $4.81 \mathrm{E}-05$ & $6.13 \mathrm{E}-04$ & $1.22 \mathrm{E}-03$ & $8.59 \mathrm{E}-05$ & $1.43 \mathrm{E}-02$ \\
\hline & MS & $1.00 \mathrm{E}+00$ & $9.98 \mathrm{E}-01^{+}$ & $1.00 \mathrm{E}+00=$ & $8.87 \mathrm{E}-01^{+}$ & $1.00 \mathrm{E}+00=$ & $9.98 \mathrm{E}-01^{+}$ & $9.96 \mathrm{E}-01^{+}$ & $1.00 \mathrm{E}+00^{+}$ & $1.00 \mathrm{E}+00^{+}$ \\
\hline & & $0.00 \mathrm{E}+00$ & $1.67 \mathrm{E}-03$ & 4.18E-05 & $5.23 \mathrm{E}-02$ & $0.00 \mathrm{E}+00$ & 2.61E-04 & $6.05 \mathrm{E}-04$ & $4.46 \mathrm{E}-05$ & $5.12 \mathrm{E}-11$ \\
\hline & GD & $1.28 \mathrm{E}-03$ & - & $1.19 \mathrm{E}-03^{-}$ & $1.06 \mathrm{E}-03^{-}$ & $1.23 \mathrm{E}-03=$ & $1.40 \mathrm{E}-03^{+}$ & $1.43 \mathrm{E}-02^{+}$ & $1.40 \mathrm{E}-03^{+}$ & $1.67 \mathrm{E}-03^{+}$ \\
\hline & GD & $3.33 \mathrm{E}-05$ & - & $8.79 E-05$ & $2.36 \mathrm{E}-03$ & $3.49 \mathrm{E}-05$ & $1.36 \mathrm{E}-04$ & $2.02 \mathrm{E}-04$ & $1.42 \mathrm{E}-04$ & $1.74 \mathrm{E}-04$ \\
\hline & & $9.01 \mathrm{E}-02$ & - & $1.01 \mathrm{E}-01^{+}$ & $2.98 \mathrm{E}-02^{-}$ & $8.45 \mathrm{E}-02=$ & $6.29 \mathrm{E}-02^{-}$ & $6.07 \mathrm{E}-02^{-}$ & $1.07 \mathrm{E}-01^{+}$ & $8.21 \mathrm{E}-02^{-}$ \\
\hline Kursawe & $\mathrm{SI}$ & 8.01E-03 & - & $4.20 \mathrm{E}-03$ & $1.03 \mathrm{E}-01$ & 3.89E-03 & $2.66 \mathrm{E}-02$ & $3.26 \mathrm{E}-03$ & $1.50 \mathrm{E}-02$ & $4.18 \mathrm{E}-03$ \\
\hline & & $1.07 \mathrm{E}-03$ & - & 9.92E-04- & $1.47 \mathrm{E}-03^{+}$ & $9.70 \mathrm{E}-04=$ & $1.32 \mathrm{E}-03^{+}$ & $9.90 \mathrm{E}-03^{+}$ & $1.33 \mathrm{E}-03^{+}$ & $1.39 \mathrm{E}-03^{+}$ \\
\hline & $\gamma$ & $5.00 \mathrm{E}-05$ & - & 7.39E-05 & $1.53 \mathrm{E}-04$ & 6.73E-05 & $1.56 \mathrm{E}-04$ & $1.77 \mathrm{E}-04$ & $1.50 \mathrm{E}-04$ & $1.41 \mathrm{E}-04$ \\
\hline & MS & $1.00 \mathrm{E}+00$ & - & $9.97 \mathrm{E}-01+0$ & $1.00 \mathrm{E}+00^{+}$ & $1.00 \mathrm{E}+00=$ & $9.99 \mathrm{E}-01^{+}$ & $9.99 \mathrm{E}-01^{+}$ & $9.99 \mathrm{E}-01^{+}$ & $6.04 \mathrm{E}-01^{+}$ \\
\hline & IVIS & 1.30E-04 & - & $1.37 \mathrm{E}-03$ & $2.18 \mathrm{E}-03$ & 1.51E-04 & $8.68 \mathrm{E}-04$ & $1.48 \mathrm{E}-03$ & $4.75 \mathrm{E}-04$ & $6.70 \mathrm{E}-02$ \\
\hline & GD & $1.18 \mathrm{E}-03$ & $5.98 \mathrm{E}-02^{+}$ & $1.23 \mathrm{E}-03^{+}$ & $1.16 \mathrm{E}-03^{-}$ & $1.23 \mathrm{E}-03^{+}$ & $1.18 \mathrm{E}-03^{+}$ & $1.14 \mathrm{E}-03^{-}$ & $1.78 \mathrm{E}-02^{+}$ & $1.19 \mathrm{E}-03^{+}$ \\
\hline & UL & $2.98 \mathrm{E}-05$ & $1.17 \mathrm{E}-03$ & $3.22 \mathrm{E}-05$ & $2.51 \mathrm{E}-05$ & $1.83 \mathrm{E}-05$ & $1.50 \mathrm{E}-05$ & $1.53 \mathrm{E}-05$ & $2.18 \mathrm{E}-04$ & $2.22 \mathrm{E}-05$ \\
\hline & & 5.11E-03 & $1.11 \mathrm{E}-02^{+}$ & $5.87 \mathrm{E}-03^{+}$ & $5.87 \mathrm{E}-03^{+}$ & $5.37 \mathrm{E}-03^{+}$ & $5.38 \mathrm{E}-03^{+}$ & $5.71 \mathrm{E}-03^{+}$ & $8.26 \mathrm{E}-03^{+}$ & $6.00 \mathrm{E}-03^{+}$ \\
\hline & SP & 4.55E-04 & $3.15 \mathrm{E}-03$ & 8.34E-04 & $6.65 \mathrm{E}-04$ & 4.63E-04 & $7.08 \mathrm{E}-04$ & $5.57 \mathrm{E}-04$ & $4.58 \mathrm{E}-04$ & 4.83E-04 \\
\hline $\mathrm{F}$ & & $1.02 \mathrm{E}-02$ & $2.64 \mathrm{E}-02^{+}$ & $1.07 \mathrm{E}-02^{+}$ & $2.38 \mathrm{E}-02^{+}$ & $1.05 \mathrm{E}-02^{+}$ & $1.02 \mathrm{E}-02^{-}$ & $9.78 \mathrm{E}-03^{-}$ & $1.52 \mathrm{E}-01^{+}$ & $2.68 \mathrm{E}-02^{+}$ \\
\hline & $\gamma$ & $3.06 \mathrm{E}-04$ & $3.75 \mathrm{E}-04$ & $3.42 \mathrm{E}-04$ & $2.91 \mathrm{E}-02$ & $1.95 \mathrm{E}-04$ & $1.24 \mathrm{E}-04$ & 1.63E-04 & $1.94 \mathrm{E}-03$ & $2.88 \mathrm{E}-02$ \\
\hline & MS & $1.00 \mathrm{E}+00$ & $4.00 \mathrm{E}-01^{+}$ & $9.99 \mathrm{E}-01^{+}$ & $5.90 \mathrm{E}-02^{+}$ & $1.00 \mathrm{E}+00=$ & $1.00 \mathrm{E}+00^{+}$ & $9.99 \mathrm{E}-01^{+}$ & $1.00 \mathrm{E}+00=$ & $4.90 \mathrm{E}-02^{+}$ \\
\hline & & 4.81E-04 & $2.98 \mathrm{E}-01$ & 7.78E-04 & $2.43 \mathrm{E}-02$ & $0.00 \mathrm{E}+00$ & $1.76 \mathrm{E}-04$ & $8.51 \mathrm{E}-04$ & 1.67E-05 & $2.05 \mathrm{E}-02$ \\
\hline$b / w / e / s$ & on GD & & $4 / 1 / 0 / 3$ & $4 / 2 / 0 / 2$ & $4 / 2 / 0 / 2$ & $4 / 0 / 2 / 4$ & $5 / 1 / 0 / 4$ & $4 / 2 / 0 / 2$ & $5 / 1 / 0 / 4$ & $5 / 1 / 0 / 4$ \\
\hline$b / w / e /$ & $m$ on SP & & $5 / 0 / 0 / 5$ & $5 / 1 / 0 / 4$ & $5 / 1 / 0 / 4$ & $4 / 1 / 1 / 3$ & $1 / 5 / 0 /-4$ & $3 / 3 / 0 / 0$ & $5 / 1 / 0 / 4$ & $2 / 4 / 0 /-2$ \\
\hline$b / w / e)$ & $m$ on $\gamma$ & & $4 / 0 / 1 / 4$ & $5 / 1 / 0 / 4$ & $6 / 0 / 0 / 6$ & $5 / 0 / 1 / 5$ & $4 / 2 / 0 / 2$ & $4 / 2 / 0 / 2$ & $5 / 1 / 0 / 4$ & $6 / 0 / 0 / 6$ \\
\hline$b / w / e / s$ & $n$ on MS & & $5 / 0 / 0 / 5$ & $4 / 0 / 2 / 4$ & $6 / 0 / 0 / 6$ & $3 / 0 / 3 / 3$ & $5 / 1 / 0 / 4$ & $5 / 1 / 0 / 4$ & $4 / 1 / 1 / 3$ & $5 / 1 / 0 / 4$ \\
\hline
\end{tabular}




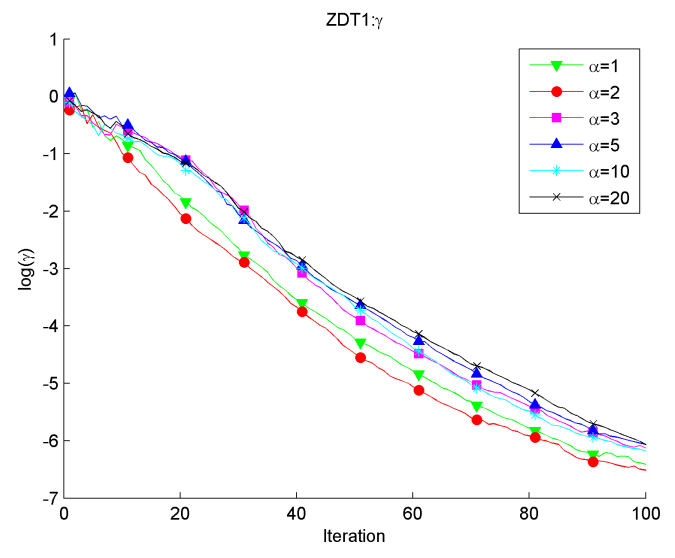

(a)

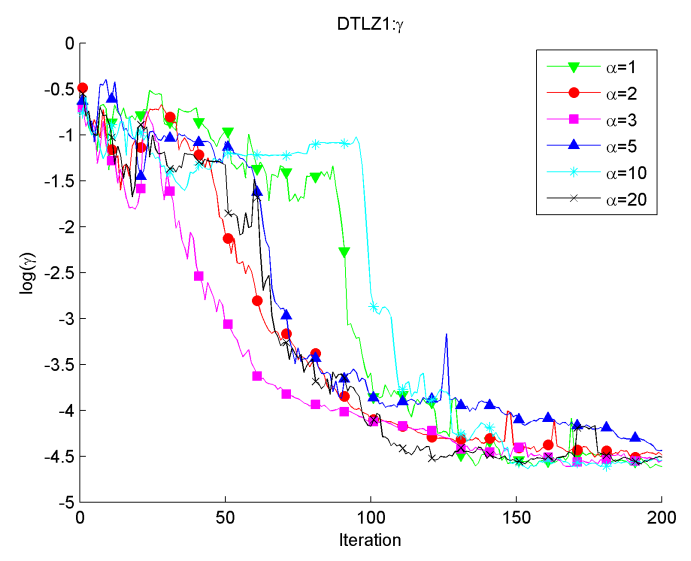

(b)

Fig. 4. Averaged convergence curves of the $\gamma$ values for the compared algorithms on (a) ZDT1 function, (b) DTLZ1 function

metrics.

The Pareto optimal solutions of ZDT6 is not uniformly distributed along the PF. The closer the solutions to the PF, the lower the density of the solutions. MOEA/CT solves the problem with the best values on GD, $\gamma$, and MS where the SP value is slightly worse than the best one that is achieved by SPEA2+SDE.

Overall, MOEA/CT obtains the best values in twelve out of the 24 test instances, followed by Two_arch2. NSGA-III and MOEA/DD cannot show the prominent results among all the test instances.

4) Comparison experiments on tri-objective problems: The experimental results of mean values and standard deviations on tri-objective problems are given in Table IV. The same statistical test is adopted as that on bi-objective problems and the statistical results are also shown in Table IV] The signs have the same meanings as those in Table III.

In total, MOEA/CT wins on 14 out of 28 comparisons and followed by MOEA/DD which wins 4 comparisons. In terms of SP value, MOEA/CT gets the best performance on almost all the seven problems except on WFG1, which shows the solutions obtained by MOEA/CT have better distribution on this test suite. The solutions of DTLZ1 function is a Pareto optimal boundary with a linear form. Smaller values of $I G D$ and $\gamma$ by SPEA2+DECOM indicate better stability with a better approximation to $\mathrm{PF}$ by the algorithm.

DTLZ2 is usually used to evaluate the performance of the algorithm when the number of objectives increases. From the results, it is obviously that the solutions obtained by MOEA/CT distribute more uniformly and has a better approximation. The smallest value of $I G D$ achieved by MOEA/CT shows the best comprehensive performance on DTLZ2.

DTLZ3 is used to test the performance of algorithms regarding converging to the PF. As shown in Table [V] all the four metrics by MOEA/CT have the best values compared to the other eight algorithms, which mean the obtained solutions can converge to the PF very closely with more uniformly distribution.

In DTLZ4, different mapping methods from the decision variables to the objective functions are used, which can well test the distribution of obtained solutions. From the values in Table IV, MOEA/DD gets the best values on IGD and $\gamma$, which shows the best performance on diversity, convergence and approximations to PF. MOEA/CT wins on GD and SP values, which show the best performance on convergence and distribution. The solutions obtained by NSGA-III always gathered together due to the maintenance of all the nondominated solutions. For Two_arch2, the distribution of nondominated solutions is not as good as that of MOEA/CT. This is duo to little interaction among the individuals during the calculation of fitness values. But in MOEA/CT, the nearby individuals enter the archive set selectively due to the external archive update strategy and diversity maintenance strategy, which help to keep the diversity of the population and obtain the solutions uniformly.

From Table IV MOEA/CT gets the best performance on GD and IGD for solving WFG1, which means the non-dominated solutions it obtained have excellent accuracy and distribution. Among the nine compared algorithms, NSGA-III achieves the best value of $S P$ on WFG1 and therefore shows the best uniformity of the non-dominated solutions, which is attributed to the reasonable reference point set. For WFG2 and WFG3, MOEA/CT gets the smallest value on $S P$, which shows that it has the better distribution performance than the other eight algorithms.

5) Supplementary experiments: The experimental results of the investigation on MOEA with and without the proposed three strategies, performance analysis along with the capacity of external archive, and comparison between SDE and CT are given in the supplementary materials.

Since MOEAs have difficulties to solve the many-objective problems (MaOPs) which are the MOPs with more than three objectives, MaOPs have attracted much more attention in recent years and several many-objective EAs have been proposed to tackle MaOPs [53] [3] [34] [56] [13]. In this paper, MOEA/CT has been shown to perform very well on the MOPs with two and three objectives. However, its scalability performance on MaOPs is unknown. Therefore, we supply the 
TABLE IV

PERFORMANCE COMPARISONS OF MOEA/CT TO DIFFERENT MOEAS WITH RESPECT TO THE AVERAGE GD, SP, $\gamma$, AND IGD VALUES ON TRI-OBJECTIVE PROBLEMS. THE BEST AVERAGE VALUES OF DIFFERENT METRICS AMONG THE NINE ALGORITHMS FOR EACH INSTANCE IS HIGHLIGHTED IN BOLD

\begin{tabular}{|c|c|c|c|c|c|c|c|c|c|c|}
\hline Function & Indicator & MOEA/CT & NSGA-III & $\begin{array}{l}\text { SPEA2+ } \\
\text { SDE }\end{array}$ & MOEA/DD & Two_arch2 & $\begin{array}{c}\text { ssNSGAII_ } \\
\text { ENLU }\end{array}$ & $\begin{array}{l}\text { MOEAD_ } \\
\text { DRA_- }_{\text {ASTM }}\end{array}$ & $\begin{array}{l}\text { SPEA2+ } \\
\text { DECOM }\end{array}$ & CMOPSO \\
\hline \multirow{8}{*}{ DTLZ1 } & \multirow{2}{*}{ GD } & $4.01 \mathrm{E}-02$ & $1.05 \mathrm{E}-02^{-}$ & $5.03 \mathrm{E}-02^{+}$ & $1.02 \mathrm{E}-02^{-}$ & $9.47 \mathrm{E}-02^{+}$ & $9.04 \mathrm{E}-01^{+}$ & $3.78 \mathrm{E}-01^{+}$ & $3.93 \mathrm{E}-02=$ & $1.81 \mathrm{E}+00^{+}$ \\
\hline & & $1.68 \mathrm{E}-02$ & $5.93 \mathrm{E}-02$ & 3.03E-02 & 1.12E-02 & $1.90 \mathrm{E}-01$ & 7.72E-01 & $3.88 \mathrm{E}-01$ & $2.09 \mathrm{E}-01$ & $1.09 \mathrm{E}+00$ \\
\hline & \multirow{2}{*}{ SP } & 4.05E-02 & $1.93 \mathrm{E}-01^{+}$ & $1.11 \mathrm{E}-01^{+}$ & $4.13 \mathrm{E}-02=$ & $5.87 \mathrm{E}-01^{+}$ & $4.42 \mathrm{E}+00^{+}$ & $3.30 \mathrm{E}+00^{+}$ & $1.02 \mathrm{E}-01^{+}$ & $4.77 \mathrm{E}+00^{+}$ \\
\hline & & 2.72E-02 & $2.37 \mathrm{E}-01$ & $1.34 \mathrm{E}-02$ & $3.65 \mathrm{E}-02$ & $1.94 \mathrm{E}+00$ & $4.31 \mathrm{E}+00$ & $3.68 \mathrm{E}+00$ & 4.64E-01 & $7.94 \mathrm{E}+00$ \\
\hline & \multirow[b]{2}{*}{$\gamma$} & $3.08 \mathrm{E}-01$ & $4.14 \mathrm{E}-01^{+}$ & $9.38 \mathrm{E}-01^{+}$ & $3.82 \mathrm{E}-01^{+}$ & $3.13 \mathrm{E}-01^{+}$ & $2.49 \mathrm{E}-01^{-}$ & $7.52 \mathrm{E}-02^{-}$ & $1.36 \mathrm{E}-02^{-}$ & $7.55 \mathrm{E}-01^{+}$ \\
\hline & & $5.59 \mathrm{E}-02$ & $1.25 \mathrm{E}-01$ & $5.71 \mathrm{E}-02$ & 8.67E-02 & 7.15E-02 & $1.10 \mathrm{E}-01$ & $7.38 \mathrm{E}-02$ & $3.88 \mathrm{E}-03$ & 7.73E-02 \\
\hline & \multirow{2}{*}{ IGD } & 3.23E-01 & $6.59 \mathrm{E}-01^{+}$ & $2.03 \mathrm{E}-01^{-}$ & $2.06 \mathrm{E}-02^{-}$ & $3.13 \mathrm{E}-01^{-}$ & 7.79E-01+ & $1.25 \mathrm{E}-01^{-}$ & 1.89E-02- & $7.37 \mathrm{E}+00^{+}$ \\
\hline & & $1.27 \mathrm{E}-01$ & 3.91E-01 & $7.21 \mathrm{E}-01$ & $4.32 \mathrm{E}-05$ & 2.04E-01 & 6.34E-01 & $1.49 \mathrm{E}-01$ & $1.60 \mathrm{E}-02$ & $4.63 \mathrm{E}+00$ \\
\hline \multirow{8}{*}{ DTLZ2 } & \multirow{2}{*}{ GD } & $6.56 \mathrm{E}-04$ & $5.89 \mathrm{E}-03^{+}$ & $4.16 \mathrm{E}-04^{-}$ & $5.08 \mathrm{E}-04^{-}$ & $6.13 \mathrm{E}-03^{+}$ & $1.00 \mathrm{E}-03^{+}$ & $6.04 \mathrm{E}-04^{-}$ & 3.18E-04- & $2.00 \mathrm{E}-03^{+}$ \\
\hline & & $1.27 \mathrm{E}-04$ & $2.79 \mathrm{E}-04$ & $4.78 \mathrm{E}-05$ & $1.19 \mathrm{E}-05$ & $1.88 \mathrm{E}-04$ & $1.84 \mathrm{E}-04$ & $2.51 \mathrm{E}-04$ & 3.18E-05 & $2.54 \mathrm{E}-04$ \\
\hline & \multirow[b]{2}{*}{ SP } & 3.84E-02 & $6.78 \mathrm{E}-02^{+}$ & $5.23 \mathrm{E}-02^{+}$ & $5.69 \mathrm{E}-02^{+}$ & $4.00 \mathrm{E}-02^{+}$ & $5.41 \mathrm{E}-02^{+}$ & $8.44 \mathrm{E}-02^{+}$ & $4.07 \mathrm{E}-02^{+}$ & $4.42 \mathrm{E}-02^{+}$ \\
\hline & & 3.39E-03 & $4.96 \mathrm{E}-03$ & $3.91 \mathrm{E}-03$ & $2.71 \mathrm{E}-04$ & 4.79E-03 & $4.52 \mathrm{E}-03$ & $3.37 \mathrm{E}-03$ & $2.00 \mathrm{E}-03$ & $2.91 \mathrm{E}-03$ \\
\hline & \multirow[b]{2}{*}{$\gamma$} & 4.48E-03 & $5.33 \mathrm{E}-02^{+}$ & $4.52 \mathrm{E}-03^{+}$ & $1.10 \mathrm{E}-02^{+}$ & $5.49 \mathrm{E}-02^{+}$ & 7.72E-03+ & $5.90 \mathrm{E}-03^{+}$ & $4.94 \mathrm{E}-03^{+}$ & $1.73 \mathrm{E}-02^{+}$ \\
\hline & & 4.79E-04 & $2.87 \mathrm{E}-03$ & $2.63 \mathrm{E}-04$ & $1.04 \mathrm{E}-02$ & $2.76 \mathrm{E}-03$ & $1.09 \mathrm{E}-03$ & 4.40E-04 & $2.48 \mathrm{E}-04$ & $1.50 \mathrm{E}-03$ \\
\hline & \multirow{2}{*}{ IGD } & 5.39E-02 & $5.82 \mathrm{E}-02^{+}$ & $7.19 \mathrm{E}-02^{+}$ & $5.45 \mathrm{E}-02^{+}$ & $5.76 \mathrm{E}-02^{+}$ & $6.75 \mathrm{E}-02^{+}$ & $6.35 \mathrm{E}-02^{+}$ & $5.54 \mathrm{E}-02^{+}$ & $5.77 \mathrm{E}-02^{+}$ \\
\hline & & 7.42E-04 & $3.89 \mathrm{E}-03$ & $3.29 \mathrm{E}-03$ & $2.62 \mathrm{E}-05$ & $2.70 \mathrm{E}-03$ & $3.16 \mathrm{E}-03$ & $1.49 \mathrm{E}-03$ & $2.42 \mathrm{E}-03$ & $9.19 \mathrm{E}-04$ \\
\hline \multirow{8}{*}{ DTLZ3 } & \multirow{2}{*}{ GD } & $6.56 \mathrm{E}-04$ & $1.44 \mathrm{E}-02^{+}$ & $1.65 \mathrm{E}-03^{+}$ & $6.79 \mathrm{E}-04^{+}$ & $6.44 \mathrm{E}-02^{+}$ & $1.98 \mathrm{E}+00^{+}$ & $8.62 \mathrm{E}-01^{+}$ & $1.27 \mathrm{E}-03^{+}$ & $5.81 \mathrm{E}+00^{+}$ \\
\hline & & 1.27E-04 & $2.45 \mathrm{E}-02$ & $6.72 \mathrm{E}-05$ & 2.29E-04 & $1.19 \mathrm{E}-01$ & $1.39 \mathrm{E}+00$ & $1.03 \mathrm{E}+00$ & $1.42 \mathrm{E}-04$ & $3.67 \mathrm{E}+00$ \\
\hline & \multirow[b]{2}{*}{ SP } & $3.84 \mathrm{E}-02$ & $8.46 \mathrm{E}-02^{+}$ & $5.25 \mathrm{E}-02^{+}$ & $5.72 \mathrm{E}-02^{+}$ & $5.77 \mathrm{E}-01^{+}$ & $8.77 \mathrm{E}+00^{+}$ & $7.02 \mathrm{E}+00^{+}$ & $3.85 \mathrm{E}-02^{+}$ & 7.63E $+00^{+}$ \\
\hline & & 3.39E-03 & $2.95 \mathrm{E}-02$ & $4.39 \mathrm{E}-03$ & $5.22 \mathrm{E}-04$ & $1.15 \mathrm{E}+00$ & $1.05 \mathrm{E}+01$ & $1.09 \mathrm{E}+01$ & $2.92 \mathrm{E}-03$ & $7.15 \mathrm{E}+00$ \\
\hline & & $4.48 E-03$ & $8.40 \mathrm{E}-02^{+}$ & $1.41 \mathrm{E}-02^{+}$ & $6.44 \mathrm{E}-01^{+}$ & $5.65 \mathrm{E}-02^{+}$ & 4.64E-01+ & $1.74 \mathrm{E}-01^{+}$ & $1.65 \mathrm{E}-02^{+}$ & $8.13 \mathrm{E}-01^{+}$ \\
\hline & $\gamma$ & 4.79E-04 & $1.13 \mathrm{E}-01$ & $5.04 \mathrm{E}-04$ & $8.96 \mathrm{E}-02$ & $2.76 \mathrm{E}-02$ & 2.02E-01 & $9.84 \mathrm{E}-02$ & $2.14 \mathrm{E}-03$ & $9.89 \mathrm{E}-02$ \\
\hline & JGD & 5.39E-02 & $1.31 \mathrm{E}-01^{+}$ & $6.44 \mathrm{E}-02^{+}$ & $5.47 \mathrm{E}-02^{+}$ & $6.46 \mathrm{E}-02^{+}$ & $6.86 \mathrm{E}+00^{+}$ & $1.30 \mathrm{E}+00^{+}$ & $6.19 \mathrm{E}-02^{+}$ & $4.61 \mathrm{E}+01^{+}$ \\
\hline & & 7.42E-04 & $2.34 \mathrm{E}-01$ & $1.30 \mathrm{E}-03$ & $3.10 \mathrm{E}-04$ & 3.04E-02 & $3.47 \mathrm{E}+00$ & 7.37E-01 & $3.31 \mathrm{E}-03$ & $3.22 \mathrm{E}+01$ \\
\hline & GD & 2.09E-03 & $5.37 \mathrm{E}-03^{+}$ & $2.73 \mathrm{E}-03^{+}$ & $5.06 \mathrm{E}-03^{+}$ & $7.61 \mathrm{E}-03^{+}$ & $2.72 \mathrm{E}-03^{+}$ & $2.84 \mathrm{E}-03^{+}$ & $4.30 \mathrm{E}-03^{+}$ & $3.17 \mathrm{E}-03^{+}$ \\
\hline & & 3.52E-04 & $5.99 \mathrm{E}-04$ & $5.79 \mathrm{E}-05$ & $1.43 \mathrm{E}-04$ & $6.42 \mathrm{E}-03$ & $6.28 \mathrm{E}-04$ & $3.68 \mathrm{E}-04$ & $2.18 \mathrm{E}-04$ & $8.29 \mathrm{E}-04$ \\
\hline & SP & $2.44 \mathrm{E}-02$ & $4.43 \mathrm{E}-02^{+}$ & $5.11 \mathrm{E}-02^{+}$ & $5.71 \mathrm{E}-02^{+}$ & $5.54 \mathrm{E}-02^{+}$ & $5.44 \mathrm{E}-02^{+}$ & $8.27 \mathrm{E}-02^{+}$ & $5.35 \mathrm{E}-02^{+}$ & $2.58 \mathrm{E}-02^{+}$ \\
\hline & SP & $1.44 \mathrm{E}-02$ & $2.55 \mathrm{E}-02$ & 4.17E-02 & $2.80 \mathrm{E}-05$ & $6.52 \mathrm{E}-02$ & $3.28 \mathrm{E}-03$ & $2.03 \mathrm{E}-03$ & $3.26 \mathrm{E}-03$ & $2.63 \mathrm{E}-03$ \\
\hline DTLZ4 & & $1.57 \mathrm{E}-01$ & $5.30 \mathrm{E}-02^{-}$ & $1.50 \mathrm{E}-02^{-}$ & $5.82 \mathrm{E}-03^{-}$ & $5.41 \mathrm{E}-02^{-}$ & $1.50 \mathrm{E}-02^{-}$ & $1.54 \mathrm{E}-02^{-}$ & 4.62E- $01^{+}$ & $7.58 \mathrm{E}-01^{+}$ \\
\hline & $\gamma$ & $2.06 \mathrm{E}-01$ & $4.93 \mathrm{E}-03$ & $5.45 \mathrm{E}-04$ & 5.33E-04 & $3.01 \mathrm{E}-03$ & $5.27 \mathrm{E}-04$ & 3.52E-04 & 8.37E-03 & $3.87 \mathrm{E}-02$ \\
\hline & IGD & 2.32E-01 & $3.05 \mathrm{E}-01^{+}$ & $6.58 \mathrm{E}-02^{-}$ & $5.45 \mathrm{E}-02-$ & $5.70 \mathrm{E}-02^{-}$ & $6.64 \mathrm{E}-02^{-}$ & $6.45 \mathrm{E}-02^{-}$ & $6.18 \mathrm{E}-02^{-}$ & $6.09 \mathrm{E}-02^{-}$ \\
\hline & & $2.38 \mathrm{E}-01$ & $3.07 \mathrm{E}-01$ & $1.56 \mathrm{E}-03$ & 7.33E-07 & $2.84 \mathrm{E}-03$ & $2.83 \mathrm{E}-03$ & $1.04 \mathrm{E}-03$ & $7.92 \mathrm{E}-03$ & $1.68 \mathrm{E}-03$ \\
\hline & GD & 6.41E-02 & $1.30 \mathrm{E}-01^{+}$ & $6.43 \mathrm{E}-02^{+}$ & $1.19 \mathrm{E}-01^{+}$ & $8.59 \mathrm{E}-02^{+}$ & $7.09 \mathrm{E}-02^{+}$ & $7.60 \mathrm{E}-02^{+}$ & $7.04 \mathrm{E}-02^{+}$ & $1.47 \mathrm{E}-01^{+}$ \\
\hline & GD & $3.56 \mathrm{E}-03$ & $4.17 \mathrm{E}-03$ & $4.69 \mathrm{E}-03$ & $1.65 \mathrm{E}-02$ & 7.67E-03 & $3.93 \mathrm{E}-03$ & $2.66 \mathrm{E}-03$ & $4.11 \mathrm{E}-03$ & $1.45 \mathrm{E}-03$ \\
\hline & & $8.20 \mathrm{E}-02$ & $3.66 \mathrm{E}-02^{-}$ & $1.00 \mathrm{E}-01^{+}$ & $3.57 \mathrm{E}-01^{+}$ & $3.69 \mathrm{E}-02^{-}$ & $1.11 \mathrm{E}-01^{+}$ & $1.98 \mathrm{E}-01^{+}$ & $1.02 \mathrm{E}-01^{+}$ & $3.47 \mathrm{E}-01^{+}$ \\
\hline WFG1 & SP & $1.51 \mathrm{E}-02$ & 4.06E-03 & $3.11 \mathrm{E}-02$ & $1.75 \mathrm{E}-01$ & $2.76 \mathrm{E}-02$ & $2.17 \mathrm{E}-02$ & $2.91 \mathrm{E}-02$ & $5.05 \mathrm{E}-02$ & $5.64 \mathrm{E}-02$ \\
\hline & & $1.80 \mathrm{E}-01$ & $1.91 \mathrm{E}+00^{+}$ & $5.74 \mathrm{E}-01^{+}$ & $4.79 \mathrm{E}-01^{+}$ & $6.54 \mathrm{E}-01^{+}$ & 3.71E-02- & $4.12 \mathrm{E}-02^{-}$ & 4.37E-02- & $4.41 \mathrm{E}-01^{+}$ \\
\hline & $\gamma$ & $8.49 \mathrm{E}-03$ & $2.03 \mathrm{E}-01$ & $1.04 \mathrm{E}-03$ & $3.14 \mathrm{E}-02$ & $6.72 \mathrm{E}-02$ & $5.29 \mathrm{E}-03$ & $2.58 \mathrm{E}-03$ & $2.10 \mathrm{E}-02$ & $6.53 \mathrm{E}-03$ \\
\hline & IGD & 1.39E-01 & $2.30 \mathrm{E}+00^{+}$ & $3.80 \mathrm{E}-01^{+}$ & $1.26 \mathrm{E}+00^{+}$ & $3.94 \mathrm{E}-01^{+}$ & 7.32E-01+ & $5.37 \mathrm{E}-01^{+}$ & $1.02 \mathrm{E}+00^{+}$ & $1.53 \mathrm{E}+00^{+}$ \\
\hline & & $1.74 \mathrm{E}-02$ & 4.22E-02 & $2.14 \mathrm{E}-02$ & $1.55 \mathrm{E}-01$ & $5.64 \mathrm{E}-02$ & $2.51 \mathrm{E}-01$ & $1.24 \mathrm{E}-01$ & $1.53 \mathrm{E}-01$ & $2.67 \mathrm{E}-02$ \\
\hline & GD & $6.38 \mathrm{E}-02$ & $5.45 \mathrm{E}-02^{-}$ & $4.63 \mathrm{E}-02^{-}$ & $8.75 \mathrm{E}^{-03}{ }^{-}$ & $5.14 \mathrm{E}-02^{-}$ & $9.41 \mathrm{E}-02^{+}$ & $6.90 \mathrm{E}-02^{+}$ & $4.38 \mathrm{E}-02^{-}$ & $2.65 \mathrm{E}-02^{-}$ \\
\hline & UD & $2.65 \mathrm{E}-03$ & $1.29 \mathrm{E}-02$ & $6.13 \mathrm{E}-03$ & $7.37 \mathrm{E}-04$ & $4.93 \mathrm{E}-03$ & $4.14 \mathrm{E}-03$ & $6.71 \mathrm{E}-03$ & $1.27 \mathrm{E}-03$ & $1.00 \mathrm{E}-02$ \\
\hline & & $7.41 \mathrm{E}-02$ & $9.77 \mathrm{E}-02^{+}$ & $1.47 \mathrm{E}-01^{+}$ & $1.29 \mathrm{E}-01^{+}$ & $1.02 \mathrm{E}-01^{+}$ & $1.99 \mathrm{E}-01^{+}$ & $2.36 \mathrm{E}-01^{+}$ & $1.09 \mathrm{E}-01^{+}$ & $1.75 \mathrm{E}-01^{+}$ \\
\hline & SP & 1.08E-02 & $2.38 \mathrm{E}-02$ & $2.28 \mathrm{E}-02$ & $2.34 \mathrm{E}-02$ & $2.31 \mathrm{E}-02$ & $3.05 \mathrm{E}-02$ & $4.02 \mathrm{E}-02$ & $1.40 \mathrm{E}-02$ & $5.09 \mathrm{E}-02$ \\
\hline & & $1.80 \mathrm{E}-01$ & $2.82 \mathrm{E}-01^{+}$ & $8.29 \mathrm{E}-02^{-}$ & $9.75 \mathrm{E}-01^{+}$ & $1.46 \mathrm{E}-01^{-}$ & $1.65 \mathrm{E}-01^{-}$ & $5.43 \mathrm{E}-02^{-}$ & $1.09 \mathrm{E}-01^{-}$ & $4.10 \mathrm{E}-02^{-}$ \\
\hline & $\gamma$ & $7.96 \mathrm{E}-03$ & $7.27 \mathrm{E}-02$ & $1.10 \mathrm{E}-02$ & $3.01 \mathrm{E}-02$ & 7.32E-03 & $1.04 \mathrm{E}-02$ & $1.07 \mathrm{E}-02$ & $2.55 \mathrm{E}-03$ & $7.58 \mathrm{E}-03$ \\
\hline & IGD & $1.44 \mathrm{E}-01$ & 7.02E-01+ & $4.60 \mathrm{E}-02^{-}$ & $4.68 \mathrm{E}-01^{+}$ & $1.46 \mathrm{E}-01^{+}$ & $1.84 \mathrm{E}-01^{+}$ & $2.41 \mathrm{E}-01^{+}$ & $1.56 \mathrm{E}-01^{+}$ & $1.64 \mathrm{E}-01^{+}$ \\
\hline & IUD & $2.01 \mathrm{E}-02$ & $3.41 \mathrm{E}-01$ & $4.17 E-03$ & $9.41 \mathrm{E}-02$ & $2.97 \mathrm{E}-02$ & $3.93 \mathrm{E}-02$ & $6.35 \mathrm{E}-02$ & $1.22 \mathrm{E}-02$ & $6.08 \mathrm{E}-03$ \\
\hline & GD & $6.73 \mathrm{E}-02$ & $6.47 \mathrm{E}-02^{-}$ & $6.87 \mathrm{E}-02^{+}$ & $7.13 \mathrm{E}-02^{+}$ & $6.75 \mathrm{E}-02^{+}$ & $7.76 \mathrm{E}-02^{+}$ & $8.06 \mathrm{E}-02^{+}$ & $7.03 \mathrm{E}-02^{+}$ & $8.98 \mathrm{E}-02^{+}$ \\
\hline & ON & $9.30 \mathrm{E}-04$ & 2.48E-03 & $1.24 \mathrm{E}-03$ & $7.62 \mathrm{E}-03$ & $9.31 \mathrm{E}-04$ & $6.47 \mathrm{E}-04$ & $1.26 \mathrm{E}-03$ & $3.08 \mathrm{E}-03$ & 2.39E-03 \\
\hline & SP & 6.38E-02 & $9.39 \mathrm{E}-02^{+}$ & $6.91 \mathrm{E}-02+$ & $1.85 \mathrm{E}-01^{+}$ & $7.11 \mathrm{E}-02^{+}$ & $9.65 \mathrm{E}-02^{+}$ & $1.55 \mathrm{E}-01^{+}$ & $1.54 \mathrm{E}-01^{+}$ & $7.56 \mathrm{E}-02^{+}$ \\
\hline WFG3 & $\mathrm{SP}$ & 1.10E-02 & $1.11 \mathrm{E}-02$ & $5.66 \mathrm{E}-03$ & 2.13E-02 & $1.15 \mathrm{E}-02$ & $1.28 \mathrm{E}-02$ & $2.55 \mathrm{E}-02$ & $9.53 \mathrm{E}-03$ & $8.35 \mathrm{E}-03$ \\
\hline WFU3 & & $1.82 \mathrm{E}-01$ & $2.44 \mathrm{E}-02^{-}$ & $3.40 \mathrm{E}-02^{-}$ & 4.64E-01+ & $1.83 \mathrm{E}-01^{+}$ & 2.03E-01+ & $3.53 \mathrm{E}-01^{+}$ & $1.98 \mathrm{E}-01^{+}$ & $2.47 \mathrm{E}-01^{+}$ \\
\hline & $\gamma$ & $2.58 \mathrm{E}-03$ & $1.56 \mathrm{E}-02$ & $5.11 \mathrm{E}-03$ & 3.64E-02 & $2.87 \mathrm{E}-03$ & $2.41 \mathrm{E}-03$ & $4.59 \mathrm{E}-02$ & $1.23 \mathrm{E}-02$ & $7.43 \mathrm{E}-03$ \\
\hline & IGD & $1.14 \mathrm{E}+00$ & $1.33 \mathrm{E}+00^{+}$ & $3.29 \mathrm{E}-01^{-}$ & $3.35 \mathrm{E}-01^{-}$ & $1.16 \mathrm{E}+00^{+}$ & $1.17 \mathrm{E}+00^{+}$ & $1.18 \mathrm{E}+00^{+}$ & $1.12 \mathrm{E}+00^{-}$ & 2.05E-01- \\
\hline & & $8.46 \mathrm{E}-03$ & $1.01 \mathrm{E}-01$ & $9.05 \mathrm{E}-03$ & $1.07 \mathrm{E}-01$ & $8.54 \mathrm{E}-03$ & $4.59 \mathrm{E}-03$ & $3.81 \mathrm{E}-02$ & $1.39 \mathrm{E}-02$ & $1.46 \mathrm{E}-02$ \\
\hline$b / w / e)$ & on GD & & $4 / 3 / 0 / 1$ & $5 / 2 / 0 / 3$ & $4 / 3 / 0 / 1$ & $6 / 1 / 0 / 5$ & $7 / 0 / 0 / 7$ & $6 / 1 / 0 / 5$ & $4 / 2 / 1 / 2$ & $6 / 1 / 0 / 5$ \\
\hline$b / w / e / s$ & $i$ on SP & & $6 / 1 / 0 / 5$ & $7 / 0 / 0 / 7$ & $6 / 0 / 1 / 6$ & $6 / 1 / 0 / 5$ & $7 / 0 / 0 / 7$ & $7 / 0 / 0 / 7$ & $7 / 0 / 0 / 7$ & $7 / 0 / 0 / 7$ \\
\hline$b / w / e /$ & $m$ on $\gamma$ & & $5 / 2 / 0 / 3$ & $4 / 3 / 0 / 1$ & $6 / 1 / 0 / 5$ & $5 / 2 / 0 / 3$ & $3 / 4 / 0 /-1$ & $3 / 4 / 0 /-1$ & $4 / 3 / 0 / 1$ & $6 / 1 / 0 / 5$ \\
\hline$b / w / e / g$ & $m$ on MS & & $7 / 0 / 0 / 7$ & $3 / 4 / 0 /-1$ & $4 / 3 / 0 / 1$ & $5 / 2 / 0 / 3$ & $6 / 1 / 0 / 5$ & $5 / 2 / 0 / 3$ & $4 / 3 / 0 / 1$ & $5 / 2 / 0 / 3$ \\
\hline
\end{tabular}


experimental results by comparing MOEA/CT with four stateof-the-art many-objective EAs on the test suites of DTLZ and WFG with 5, 8, 10 and 15 objectives. The results are also given in the supplementary material.

\section{CONCLUSiON}

In this paper, a MOEA/CT has been proposed for better managing convergence and distribution of solutions when MOEAs are used for solving MOPs. The main idea in MOEA/CT is the coordinate transformation strategy that helps to find more efficient solutions. Based on the coordinate transformation strategy, a novel strategy that selects solutions from the nondominated solution set and the $L_{p}$-norm strategy that is used to get good distribution of the solutions are integrated in MOEA/CT. The comparative experiments are performed on ZDT, DTLZ, and WFG test suites. In terms of four performance metrics, the proposed MOEA/CT outperforms the other eight state-of-the-art competitors not only on the linear MOPs but also on the complex non-linear MOPs. In the future, we will examine the proposed algorithm on highdimensional problems, many-objective optimization problems, and real-world MOPs.

\section{REFERENCES}

[1] C. C. Aggarwal, A. Hinneburg, and D. A. Keim, On the Surprising Behavior of Distance Metrics in High Dimensional Space. Springer Berlin Heidelberg, 2001.

[2] N. Al Moubayed, A. Petrovski, and J. McCall, "D2mopso: Mopso based on decomposition and dominance with archiving using crowding distance in objective and solution spaces," Evolutionary computation, vol. 22, no. 1, pp. 47-77, 2014.

[3] M. Asafuddoula, T. Ray, and R. Sarker, "A decomposition-based evolutionary algorithm for many objective optimization," IEEE Transactions on Evolutionary Computation, vol. 19, no. 3, pp. 445-460, 2015.

[4] J. Bader and E. Zitzler, "Hype: An algorithm for fast hypervolume-based many-objective optimization," Evolutionary computation, vol. 19, no. 1, pp. 45-76, 2011.

[5] S. K. Bailey, Annals of the American Academy of Political and Social Science. Published by A.L. Hummel for the American Academy of Political and Social Science, 2012.

[6] S. Bandyopadhyay and A. Mukherjee, "An algorithm for many-objective optimization with reduced objective computations: A study in differential evolution," IEEE transactions on Evolutionary Computation, vol. 19, no. 3, pp. 400-413, 2015.

[7] N. Beume, B. Naujoks, and M. Emmerich, "Sms-emoa: Multiobjective selection based on dominated hypervolume," European Journal of Operational Research, vol. 181, no. 3, pp. 1653-1669, 2007.

[8] M. S. Bittermann and O. Ciftcioglu, "Architectural design computing supported by multi-objective optimization," in Evolutionary Computation, 2015.

[9] D. Brockhoff and E. Zitzler, "Improving hypervolume-based multiobjective evolutionary algorithms by using objective reduction methods," in Evolutionary Computation, 2007. CEC 2007. IEEE Congress on. IEEE, 2007, pp. 2086-2093.

[10] X. Cai, Z. Mei, and Z. Fan, “A decomposition-based many-objective evolutionary algorithm with two types of adjustments for direction vectors," IEEE Transactions on Cybernetics, pp. 1-14, 2018.

[11] X. Cai, Z. Yang, Z. Fan, and Q. Zhang, "Decomposition-based-sorting and angle-based-selection for evolutionary multiobjective and manyobjective optimization," IEEE Transactions on Cybernetics, vol. 47, no. 9, pp. 2824-2837, Sept 2017.

[12] X. Cai, Y. Li, Z. Fan, and Q. Zhang, "An external archive guided multiobjective evolutionary algorithm based on decomposition for combinatorial optimization," IEEE Transactions on Evolutionary Computation, vol. 19, no. 4, pp. 508-523, 2015.

[13] R. Cheng, Y. Jin, M. Olhofer, and B. Sendhoff, "A reference vector guided evolutionary algorithm for many-objective optimization," IEEE Transactions on Evolutionary Computation, vol. 20, no. 5, pp. 773-791, 2016.
[14] C. A. C. Coello, G. T. Pulido, and M. S. Lechuga, "Handling multiple objectives with particle swarm optimization," IEEE Transactions on Evolutionary Computation, vol. 8, no. 3, pp. 256-279, 2004.

[15] K. Deb and H. Jain, "An evolutionary many-objective optimization algorithm using reference-point-based nondominated sorting approach, part i: Solving problems with box constraints," IEEE Transactions on Evolutionary Computation, vol. 18, no. 4, pp. 577-601, 2014.

[16] K. Deb, A. Pratap, S. Agarwal, and T. Meyarivan, "A fast and elitist multiobjective genetic algorithm: Nsga-ii," IEEE Transactions on Evolutionary Computation, vol. 6, no. 2, pp. 182-197, 2002.

[17] K. Deb, "Construction of test problems for multi-objective optimization." in Genetic and Evolutionary Computation Conference, 1999, pp. 164171.

[18] — , "Multi-objective genetic algorithms: Problem difficulties and construction of test problems," Evolutionary Computation, vol. 7, no. 3 , pp. 205-230, 1999.

[19] - Multi-objective optimization using evolutionary algorithms. John Wiley \& Sons, 2001, vol. 16

[20] K. Deb, S. Agrawal, A. Pratap, and T. Meyarivan, "A fast elitist nondominated sorting genetic algorithm for multi-objective optimisation: Nsga-ii," in Parallel Problem Solving From Nature Vi, 2000, pp. 849858.

[21] K. Deb, L. Thiele, M. Laumanns, and E. Zitzler, "Scalable multiobjective optimization test problems," in Evolutionary Computation, 2002. CEC '02. Proceedings of the 2002 Congress on, 2002, pp. 825830.

[22] S. B. Gee, K. C. Tan, and C. Alippi, "Solving multiobjective optimization problems in unknown dynamic environments: An inverse modeling approach," IEEE Transactions on Cybernetics, vol. 47, no. 12, pp. 42234234, Dec 2017.

[23] S. Huband, P. Hingston, L. Barone, and L. While, "A review of multiobjective test problems and a scalable test problem toolkit," IEEE Transactions on Evolutionary Computation, vol. 10, no. 5, pp. 477-506, 2006.

[24] S. Jiang and S. Yang, "An improved multiobjective optimization evolutionary algorithm based on decomposition for complex pareto fronts," IEEE transactions on cybernetics, vol. 46, no. 2, pp. 421-437, 2016.

[25] L. Ke, Q. Zhang, and R. Battiti, "Moea/d-aco: A multiobjective evolutionary algorithm using decomposition and antcolony," IEEE transactions on cybernetics, vol. 43, no. 6, pp. 1845-1859, 2013.

[26] H. T. Kung, F. Luccio, and F. P. Preparata, "On finding the maxima of a set of vectors," Journal of the Acm, vol. 22, no. 4, pp. 469-476, 1975.

[27] M. Laumanns, E. Zitzler, and L. Thiele, "A unified model for multiobjective evolutionary algorithms with elitism," in Evolutionary Computation, 2000. Proceedings of the 2000 Congress on, 2000, pp. 46-53 vol.1.

[28] B. Li, K. Tang, J. Li, and X. Yao, "Stochastic ranking algorithm for many-objective optimization based on multiple indicators," IEEE Transactions on Evolutionary Computation, vol. 20, no. 6, pp. 924-938, 2016.

[29] H. Li and D. Landa-Silva, "An adaptive evolutionary multi-objective approach based on simulated annealing," Evolutionary Computation, vol. 19, no. 4, pp. 561-595, 2011.

[30] K. Li, K. Deb, Q. Zhang, and S. Kwong, "An evolutionary manyobjective optimization algorithm based on dominance and decomposition," IEEE Transactions on Evolutionary Computation, vol. 19, no. 5, pp. 694-716, Oct 2015.

[31] K. Li, K. Deb, Q. Zhang, and Q. Zhang, "Efficient nondomination level update method for steady-state evolutionary multiobjective optimization," IEEE Transactions on Cybernetics, vol. 47, no. 9, pp. 2838-2849, Sept 2017.

[32] M. Li, S. Yang, J. Zheng, and X. Liu, "Etea: a euclidean minimum spanning tree-based evolutionary algorithm for multi-objective optimization." Evolutionary Computation, vol. 22, no. 2, pp. 189 - 230, 2014

[33] M. Li, S. Yang, and X. Liu, "Shift-based density estimation for paretobased algorithms in many-objective optimization," IEEE Transactions on Evolutionary Computation, vol. 18, no. 3, pp. 348-365, 2014.

[34] _ "Bi-goal evolution for many-objective optimization problems," Artificial Intelligence, vol. 228, no. Supplement C, pp. 45-65, 2015. [Online]. Available: http://www.sciencedirect.com/science/article/ pii/S0004370215000995

[35] $=$ "Pareto or non-pareto: Bi-criterion evolution in multiobjective optimization," IEEE Transactions on Evolutionary Computation, vol. 20, no. 5, pp. 645-665, 2016.

[36] D. Liu, K. C. Tan, C. K. Goh, and W. K. Ho, "A multiobjective memetic algorithm based on particle swarm optimization." IEEE Transactions on Systems Man Cybernetics Part B, vol. 37, no. 1, pp. 42-50, 2007. 
[37] A. Muruganantham, K. C. Tan, and P. Vadakkepat, "Evolutionary dynamic multiobjective optimization via kalman filter prediction," IEEE Transactions on Cybernetics, vol. 46, no. 12, pp. 2862-2873, Dec 2016.

[38] D. H. Non-Member, R. G. Non-Member, and N. M. Shu, "Constrained multiobjective optimization for microgrid based on nondominated immune algorithm," Ieej Transactions on Electrical \& Electronic Engineering, vol. 10, no. 4, p. 376-382, 2015.

[39] S. K. Panda and P. K. Jana, "A multi-objective task scheduling algorithm for heterogeneous multi-cloud environment," in International Conference on Electronic Design, Computer Networks \& Automated Verification, 2015, pp. 82-87.

[40] I. D. Psychas, E. Delimpasi, and Y. Marinakis, "Hybrid evolutionary algorithms for the multiobjective traveling salesman problem," Expert Systems with Applications, vol. 42, no. 22, p. 8956-8970, 2015.

[41] N. Srinivas and K. Deb, "Muiltiobjective optimization using nondominated sorting in genetic algorithms," Evolutionary computation, vol. 2, no. 3, pp. 221-248, 1994

[42] K. C. Tan, T. H. Lee, and E. F. Khor, "Evolutionary algorithms with dynamic population size and local exploration for multiobjective optimization," IEEE Transactions on Evolutionary Computation, vol. 5, no. 6, pp. 565-588, 2001

[43] Y. Tian, R. Cheng, X. Zhang, and Y. Jin, "Platemo: A matlab platform for evolutionary multi-objective optimization [educational forum]," IEEE Computational Intelligence Magazine, vol. 12, no. 4, pp. 73-87, 2017.

[44] A. Trivedi, D. Srinivasan, K. Sanyal, and A. Ghosh, "A survey of multiobjective evolutionary algorithms based on decomposition," IEEE Transactions on Evolutionary Computation, vol. 21, no. 3, pp. 440-462, 2017.

[45] D. A. V. Veldhuizen and G. B. Lamont, "On measuring multiobjective evolutionary algorithm performance," in Evolutionary Computation, 2000. Proceedings of the 2000 Congress on, 2000, pp. 204-211 vol.1.

[46] S. M. Venske, R. A. Gonçalves, and M. R. Delgado, "Ademo/d: Multiobjective optimization by an adaptive differential evolution algorithm," Neurocomputing, vol. 127, pp. 65-77, 2014.

[47] H. Wang, L. Jiao, and X. Yao, "Two_arch2: An improved two-archive algorithm for many-objective optimization," IEEE Transactions on Evolutionary Computation, vol. 19, no. 4, pp. 524-541, 2015.

[48] J. Wang, G. Liang, and J. Zhang, "Cooperative differential evolution framework for constrained multiobjective optimization," IEEE Transactions on Cybernetics, pp. 1-13, 2018.

[49] L. Wang, Q. Zhang, A. Zhou, M. Gong, and L. Jiao, "Constrained subproblems in a decomposition-based multiobjective evolutionary algorithm," IEEE Transactions on Evolutionary Computation, vol. 20, no. 3, pp. 475-480, 2016.

[50] M. Wu, K. Li, S. Kwong, Y. Zhou, and Q. Zhang, "Matching-based selection with incomplete lists for decomposition multiobjective optimization," IEEE Transactions on Evolutionary Computation, vol. 21 no. 4, pp. 554-568, Aug 2017.

[51] Y. Xiang, Y. Zhou, L. Tang, and Z. Chen, "A decomposition-based many-objective artificial bee colony algorithm," IEEE Transactions on Cybernetics, pp. 1-14, 2017.

[52] S. Yang, S. Jiang, and Y. Jiang, "Improving the multiobjective evolutionary algorithm based on decomposition with new penalty schemes," Soft Computing, vol. 21, no. 16, pp. 4677-4691, 2017.

[53] S. Yang, M. Li, X. Liu, and J. Zheng, "A grid-based evolutionary algorithm for many-objective optimization," IEEE Transactions on Evolutionary Computation, vol. 17, no. 5, pp. 721-736, 2013.

[54] X. Yu, W. N. Chen, T. Gu, H. Zhang, H. Yuan, S. Kwong, and J. Zhang, "Set-based discrete particle swarm optimization based on decomposition for permutation-based multiobjective combinatorial optimization problems," IEEE Transactions on Cybernetics, pp. 1-15, 2018.

[55] Y. Yuan, H. Xu, B. Wang, B. Zhang, and X. Yao, "Balancing convergence and diversity in decomposition-based many-objective optimizers," IEEE Transactions on Evolutionary Computation, vol. 20, no. 2, pp. 180-198, 2016

[56] Y. Yuan, H. Xu, B. Wang, and X. Yao, "A new dominance relationbased evolutionary algorithm for many-objective optimization," IEEE Transactions on Evolutionary Computation, vol. 20, no. 1, pp. 16-37, 2016.

[57] S. Zapotecas-Martínez, B. Derbel, A. Liefooghe, H. E. Aguirre, and K. Tanaka, "Geometric differential evolution in moea/d: a preliminary study," in Mexican International Conference on Artificial Intelligence. Springer, 2015, pp. 364-376.

[58] S. Zeng, R. Jiao, C. Li, X. Li, and J. S. Alkasassbeh, "A general framework of dynamic constrained multiobjective evolutionary algorithms for constrained optimization," IEEE Transactions on Cybernetics, vol. 47, no. 9, pp. 2678-2688, Sept 2017.
[59] Q. Zhang and H. Li, "Moea/d: A multiobjective evolutionary algorithm based on decomposition," IEEE Transactions on Evolutionary Computation, vol. 11, no. 6, pp. 712-731, 2007.

[60] X. Zhang, Y. Tian, and Y. Jin, "A knee point driven evolutionary algorithm for many-objective optimization," IEEE Transactions on Evolutionary Computation, vol. 19, 2015.

[61] X. Zhang, Y. Tian, R. Cheng, and Y. Jin, "An efficient approach to nondominated sorting for evolutionary multi-objective optimization," IEEE Transactions on Evolutionary Computation, vol. 19, no. 2, pp. 201-213, 2015.

[62] X. Zhang, X. Zheng, R. Cheng, J. Qiu, and Y. Jin, "A competitive mechanism based multi-objective particle swarm optimizer with fast convergence," Information Sciences, vol. 427, pp. 63 - 76, 2018. [Online]. Available: http://www.sciencedirect.com/science/article/ pii/S0020025517310344

[63] Y. Zhang, D. wei Gong, J. yong Sun, and B. yang $\mathrm{Qu}$, "A decomposition-based archiving approach for multiobjective evolutionary optimization," Information Sciences, vol. 430-431, pp. $397-413$, 2018. [Online]. Available: http://www.sciencedirect.com/science/article/pii/S0020025517311143

[64] J.-H. Zheng, R.-M. Shen, M.-Q. Li, and J. Zou, "Evolutionary algorithm based on information separation for many-objective optimization," Journal of Software, vol. 26, no. 5, pp. 1013-1036, 2015.

[65] A. Zhou and Q. Zhang, "Are all the subproblems equally important? resource allocation in decomposition-based multiobjective evolutionary algorithms," IEEE Transactions on Evolutionary Computation, vol. 20, no. 1, pp. 52-64, 2016.

[66] E. Zitzler, L. Thiele, M. Laumanns, C. M. Fonseca, and V. G. D. Fonseca, "Performance assessment of multiobjective optimizers: an analysis and review," IEEE Transactions on Evolutionary Computation, vol. 7, no. 2, pp. 117-132, 2003.

[67] E. Zitzler and S. Künzli, "Indicator-based selection in multiobjective search," in International Conference on Parallel Problem Solving from Nature. Springer, 2004, pp. 832-842.

[68] E. Zitzler, M. Laumanns, and L. Thiele, "Spea2: Improving the strength pareto evolutionary algorithm," in Evolutionary Methods for Design, Optimization and Control., 2001, pp. 95-100.

[69] E. Zitzler and L. Thiele, "Multiobjective evolutionary algorithms: a comparative case study and the strength pareto approach," IEEE Transactions on Evolutionary Computation, vol. 3, no. 4, pp. 257-271, 1999.

[70] Y. Zuo, M. Gong, J. Zeng, and L. Ma, "Personalized recommendation based on evolutionary multi-objective optimization [research frontier]," IEEE Computational Intelligence Magazine, vol. 10, no. 1, pp. 52-62, 2015.

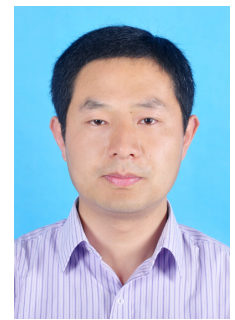

Wei Fang (M'15) received the Ph.D. degree in information technology and engineering of light industry from Jiangnan University, Wuxi, China, in 2008. He is an Associate Professor of computer science at Jiangnan University. He was a Visiting Scholar at the CEACIA, University of Birmingham, Birmingham, U.K from April 2013 to April 2014. He has published more than 50 scientific papers in journals and international conferences. His current research interests involve the evolutionary computation, swarm intelligence, multi-objective optimization, and largescale global optimization. He serves as an Editorial Board Member of International Journal of Swarm Intelligence Research and International Journal of Computing Science and Mathematics. 


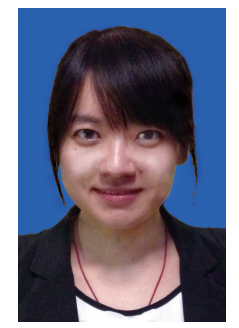

Lingzhi Zhang received the B.Sc. degree and the M.Sc. degree from Jiangnan University, China, in 2013 and 2017 respectively. She is currently an assistant engineer in Network Information and Operation Center of Jiangnan University. Her current research interests include evolutionary computation, multi-objective optimization, and dynamic optimization.

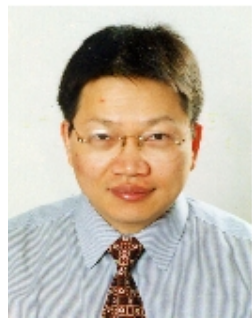

Shengxiang Yang (M'00-SM'14) received the $\mathrm{Ph}$.D. degree from Northeastern University, China in 1999. He is currently a Professor in Computational Intelligence and Director of the Centre for Computational Intelligence, School of Computer Science and Informatics, De Montfort University, Leicester, U.K. He has over 250 publications. His current research interests include evolutionary computation, swarm intelligence, artificial neural networks, data mining and data stream analysis, and relevant real-world applications. He serves as an Associate Editor/Editorial Board Member of seven international journals, such as the IEEE Transactions on Cybernetics, Information Sciences, Evolutionary Computation, and Soft Computing.

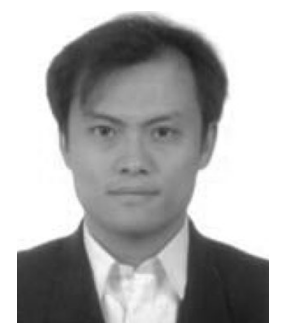

Jun Sun received his Ph.D. degree in control theory and engineering, and an MSc in Computer Science and Technology from Jiangnan University, China, in 2009 and 2003, respectively. He is currently working as a full Professor with the Department of Computer Science and Technology, Jiangnan University, China. He is also vice director of Jiangsu Provincial Engineering Laboratory of Pattern Recognition and Computational Intelligence, Jiangsu Province. His major research areas and work are related to computational intelligence, machine learning, bioinformatics, among others. He published more than 150 papers in journals, conference proceedings and several books in the above areas.

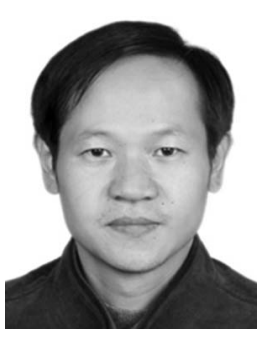

intelligent systems.
Xiao-Jun Wu received the B.Sc. degree in mathematics from Nanjing Normal University, Nanjing, China, in 1991, and the M.S. degree in computer science and the Ph.D. degree in pattern recognition and intelligent systems from the Nanjing University of Science and Technology, Nanjing, in 1996 and 2002, respectively. He is currently a Professor of Artificial Intelligent and Pattern Recognition with Jiangnan University, Wuxi, China. His current research interests include pattern recognition, computer vision, fuzzy systems, neural networks, and 


\title{
Supplemental Material for A Multi-objective Evolutionary Algorithm Based on Coordinate Transformation
}

\author{
Wei Fang, Member, IEEE, Lingzhi Zhang, Shengxiang Yang Senior Member, IEEE, Jun Sun, Xiaojun Wu
}

\section{INVESTIGATE THE PERFORMANCE OF THE PROPOSED THREE STRATEGIES IN MOEA/CT}

In MOEA/CT, three strategies, which are the CT strategy, the external archive update strategy, and the diversity maintenance strategy, have been proposed. For the purpose of investigating these three strategies to the performance of the algorithm, we take ZDT1 and ZDT2 as the test functions and study these strategies by integrating them one by one into the MOEA framework. The indicators GD, SP, and $\gamma$ are used to evaluate the performance. Here, MOEA with the CT strategy alone is termed as MOEA/TF, and then the external archive strategy is introduced and termed as MOEA/TFS. For MOEA/TF, only the individuals with small values of $\mathrm{O}_{i}^{\prime \prime}$ can survive in the the external archive until the archive is full. The comparison results among MOEA/TF, MOEA/TFS, and MOEA/CT are shown in Table [1] which are the mean values over 30 independent runs with each run lasting for 100 iterations.

TABLE I

COMPARISON RESULTS AMONG MOEA/TF, MOEA/TFS, AND MOEA/CT FOR EVALUATING THE THREE STRATEGIES

\begin{tabular}{lcccc}
\hline \multicolumn{1}{c}{ Algorithms } & Functions & GD & SP & $\gamma$ \\
\hline MOEA & & $6.54 \mathrm{E}-02$ & $5.94 \mathrm{E}-01$ & $8.25 \mathrm{E}-01$ \\
MOEA/TF & \multirow{2}{*}{ ZDT1 } & $9.33 \mathrm{E}-04$ & $1.60 \mathrm{E}-02$ & $6.79 \mathrm{E}-03$ \\
MOEA/TFS & & $3.59 \mathrm{E}-04$ & $1.12 \mathrm{E}-02$ & $1.65 \mathrm{E}-03$ \\
MOEA/CT & & $\mathbf{3 . 0 1 E - 0 4}$ & $\mathbf{6 . 7 8 E - 0 3}$ & $\mathbf{1 . 5 1 E - 0 3}$ \\
\hline MOEA & & $3.27 \mathrm{E}-01$ & $6.32 \mathrm{E}-01$ & $5.61 \mathrm{E}-01$ \\
MOEA/TF & \multirow{2}{*}{ ZDT2 } & $7.88 \mathrm{E}-04$ & $2.04 \mathrm{E}-02$ & $5.55 \mathrm{E}-03$ \\
MOEA/TFS & & $1.02 \mathrm{E}-04$ & $1.43 \mathrm{E}-02$ & $2.41 \mathrm{E}-02$ \\
MOEA/CT & & $\mathbf{9 . 2 9 E - 0 5}$ & $\mathbf{5 . 6 8 E - 0 3}$ & $\mathbf{8 . 0 0 E - 0 4}$ \\
\hline
\end{tabular}

It is clearly that the proposed three strategies works better with MOEA. The values of GD and $\gamma$ obtained by MOEA/TF are smaller than those obtained by MOEA, which tells us that

This work was supported in part by the National Natural Science foundation of China (Grant Nos. 61673194, 61672263, 61105128), Key Research and Development Program of Jiangsu Province, China (Grant No. BE2017630), the Postdoctoral Science Foundation of China (Grant No. 2014M560390), Six Talent Peaks Project of Jiangsu Province (Grant No. DZXX-025).

W. Fang, J. Sun, X. Wu are with the Jiangsu Provincial Engineering Laboratory of Pattern Recognition and Computational Intelligence, the Department of Computer Science and Technology, Jiangnan University, Wuxi, China. Email: fangwei@jiangnan.edu.cn, sunjun_wx@hotmail.com, wu_xiaojun@jiangnan.edu.cn.

L. Zhang is with the Network Information and Operation Center, Jiangnan University, Wuxi, China. Email: zhanglingzhi@jiangnan.edu.cn

$\mathrm{S}$. Yang is with the Centre for Computational Intelligence (CCI), School of Computer Science and Informatics, De Montfort University, Leicester LE1 9BH, UK. Email: syang@dmu.ac.uk. the CT strategy helps MOEA to achieve better approximation to the Pareto optimal front. However, with the evolutionary process, the number of non-dominated solutions increases quickly, just relying on the CT strategy cannot promise to select the solutions effectively. Therefore, the external archive strategy is proposed. From the table, MOEA/TFS has better performance than MOEA/TF concerning the indicators GD and $\gamma$, which shows the validity of the external archive

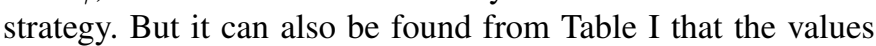
of SP obtained by MOEA/TF and MOEA/TFS are worse than those by MOEA/CT. This reflects the effectiveness of the proposed diversity maintenance strategy where much better distribution of solutions can be got.

\section{Performance ANAlysis REgARDing THE CAPACITY OF EXTERNAL ARCHIVE}

The external archive is used to store the individuals that have good performance on convergence. It is necessary to make clear that how the capacity of external archive influences the performance of MOEA/CT. Here, the population size is 100 and the capacity of external archive is set to be $80 \%, 100 \%$, $120 \%$, and $140 \%$ of the population size. ZDT1 and ZDT3 are used for testing. The mean values and standard deviations of $\mathrm{GD}$, SP, and $\gamma$ over 30 individual independent runs are given in Table [I]

TABLE II

EXPERIMENTAL RESULTS OF MOEA/CT WITH DIFFERENT CAPACITIES OF EXTERNAL ARCHIVE

\begin{tabular}{|c|c|c|c|c|c|}
\hline & & $80 \%$ & $100 \%$ & $120 \%$ & $140 \%$ \\
\hline \multirow{6}{*}{ ZDT1 } & \multirow[t]{2}{*}{ GD } & $3.02 \mathrm{E}-04$ & $3.01 \mathrm{E}-04$ & $3.01 \mathrm{E}-04$ & $3.02 \mathrm{E}-04$ \\
\hline & & $4.03 \mathrm{E}-06$ & $3.35 \mathrm{E}-06$ & 4.79E-06 & $9.46 \mathrm{E}-06$ \\
\hline & \multirow[t]{2}{*}{ SP } & $6.78 \mathrm{E}-03$ & $6.78 \mathrm{E}-03$ & $6.85 \mathrm{E}-03$ & $6.85 \mathrm{E}-03$ \\
\hline & & $3.05 \mathrm{E}-04$ & $2.10 \mathrm{E}-04$ & $1.15 \mathrm{E}-04$ & $1.81 \mathrm{E}-04$ \\
\hline & \multirow[t]{2}{*}{$\gamma$} & $1.51 \mathrm{E}-03$ & $1.51 \mathrm{E}-03$ & $1.51 \mathrm{E}-03$ & $1.51 \mathrm{E}-03$ \\
\hline & & $3.04 \mathrm{E}-05$ & $2.50 \mathrm{E}-05$ & $2.57 \mathrm{E}-05$ & 4.19E-05 \\
\hline \multirow{6}{*}{ ZDT3 } & \multirow[t]{2}{*}{ GD } & $6.74 \mathrm{E}-04$ & $6.73 \mathrm{E}-04$ & $6.73 \mathrm{E}-04$ & $6.74 \mathrm{E}-04$ \\
\hline & & $5.30 \mathrm{E}-06$ & $3.71 \mathrm{E}-06$ & $1.02 \mathrm{E}-06$ & $3.77 \mathrm{E}-06$ \\
\hline & \multirow[t]{2}{*}{ SP } & $6.64 \mathrm{E}-03$ & $5.74 \mathrm{E}-03$ & $5.74 \mathrm{E}-03$ & $5.75 \mathrm{E}-03$ \\
\hline & & $2.94 \mathrm{E}-04$ & $1.21 \mathrm{E}-04$ & $1.22 \mathrm{E}-04$ & $1.22 \mathrm{E}-05$ \\
\hline & \multirow[t]{2}{*}{$\gamma$} & $2.87 \mathrm{E}-03$ & $2.88 \mathrm{E}-03$ & $2.88 \mathrm{E}-03$ & $2.88 \mathrm{E}-03$ \\
\hline & & $3.38 \mathrm{E}-05$ & $1.52 \mathrm{E}-05$ & 4.61E-05 & $4.58 \mathrm{E}-05$ \\
\hline
\end{tabular}

From the values of GD and $\gamma$ for ZDT1, the capacity of external archive has little influence on the performance of the algorithm. For ZDT3, when the capacity of external archive is $100 \%$ or $120 \%$ to the population size, the algorithm has better performance and the algorithm is more stable when 
the capacity equals to the population size. Therefore, from the overall results, we know that the best performance of MOEA/CT can be achieved when the capacity of external archive equals to the population size and the rule is used in this paper.

\section{Performance comparison with the notable} MANY-OBJECTIVE EVOLUTIONARY ALGORITHMS

For further studying the performance of MOEA/CT, five notable many-objective evolutionary algorithms published in recent years are included for comparison in the study, which are GrEA [7], I-DBEA [1], $\theta$-DEA [8], RVEA [2], and AR-MOEA [5]. The five algorithms are implemented in the PlatEMO [6]. The specific parameter settings for each algorithm follows the guidelines recommended by the authors. The experiments are carried out on CEC 2009 unconstrained test problems [9], DTLZ1 to DTLZ4 problems [3] and WFG1 to WFG9 problems with $5,8,10,15$ objectives [4]. Table III shows the settings of all the test problems. For each test problem, each algorithm was run 30 independent times with a population size of 100 . The maximum number of generations was used as the termination condition for each run and was set to different values for different test problems.

The Wilcoxon rank sum test is carried out to compare the results between MOEA/CT and the other four compared algorithms at a significance level of 0.05 . In Tables IV] $\mathrm{V}$, and VI, the symbols "+",",", and "=" indicate that MOEA/CT is significantly better than, significantly worse than, and statistically similar to the compared algorithm, respectively, according to the Wilcoxon rank sum test; the term ' $b / w / e$ ' indicates the number of functions that MOEA/CT performs significantly better than, significantly worse than, and statistically equivalent to the compared algorithm; and ' $g m$ ' is the difference between the term ' $b$ ' and ' $w$ ' in order to show the overall comparison between MOEA/CT and the compared algorithm.

TABLE III

SETTINGS FOR TEST PROBLEMS

\begin{tabular}{llll}
\hline Problems & $\begin{array}{l}\text { Number of } \\
\text { Objectives }(M)\end{array}$ & $\begin{array}{l}\text { Number of } \\
\text { Variables }(n)\end{array}$ & Parameter \\
\hline UF1 UF7 & 2 & 30 & \\
UF8 UF10 & 3 & 30 & \\
DTLZ1 & $5,8,10,15$ & $M+K-1$ & $K=5$ \\
DTLZ2 $\sim$ DTLZ4 & $5,8,10,15$ & $M+K-1$ & $K=10$ \\
WFG1 $\sim$ WFG9 & 5 & $L+K$ & $L=4, K=20$ \\
WFG1 $\sim$ WFG9 & 8 & $L+K$ & $L=4, K=20$ \\
WFG1 $\sim$ WFG9 & 10 & $L+K$ & $L=7, K=17$ \\
WFG1 $\sim$ WFG9 & 15 & $L+K$ & $L=18, K=6$ \\
\hline
\end{tabular}

\section{A. The CEC 2009 unconstrained test problems}

Zhang et. al. designed the CEC 2009 multi-objective optimization test problems which resemble the real-life problems in order to promote the research in MOEAs [9]. In this paper, we use the unconstrained MOP test problems (UF1 to UF10) to further evaluate the proposed MOEA/CT and compare its performance with the four notable many-objective evolutionary algorithms. The performance metrics GD and IGD are taken to compare the selected algorithms. The maximum generations for each run is 500 with the population size 100 .

Table IV] shows the GD and IGD values in terms of the mean value and standard deviation over 30 independent runs and the best mean results are shown in bold. From Table IV MOEA/CT, together with GrEA and AR-MOEA, performs the best among the six compared algorithms on all the test problems and MOEA/CT achieves the best results on 8 out of 10 instances.

\section{B. The DTLZ1, DTZL2, DTLZ3, and DTLZ4 test problems}

DTLZ1 to DTLZ4 are normalized test problems with the same range for each objective over the PF. For DTLZ1 and DTLZ3, it is difficulty for an algorithm to converge into the PF since more obstacles lie in the test problems. For DTLZ2 and DTLZ4, they are designed with various shapes and locations to evaluate different capacities of an algorithm. The performance metric IGD is selected to evaluate the performance of each algorithm. The experimental results of the IGD values in terms of the mean and standard deviation obtained by five algorithms on DTLZ test problems are given in Table $\mathrm{V}$ and the best mean results are in bold. From Table V, it is clear that MOEA/CT only show the best performance on 5-objective instances of DTLZ2, and DTLZ4, where RVEA shows the best performance on all DTLZ1 and DTLZ3 instances. GrEA obtains the best performance on 8-objective and 15-objective instances of DTLZ2 and DTLZ4. For $\theta$-DEA, it achieves the best performance on 10-objective instances of DTLZ2 and DTLZ4. As can be observed from the $g m$ values in Table V], MOEA/CT runs the worst on this set of problems, which indicates that MOEA/CT is not suitable for this kind of normalized test problems with high dimensions.

\section{The WFG1 to WFG9 test problems}

The scaled problems of WFG1 to WFG9 are designed by employing different types of difficulties both in the objective space and decision space. For WFG1, it has a mixed PF. WFG2 has a disconnected and convex PF. However, the PF of WFG3 is linear and degenerate. The problems of WFG4 to WFG9 have concave PFs. For WFG2, WFG3, WFG6, WFG8, and WFG9, they are all non-separable. As reported in Table VI MOEA/CT shows the most competitive overall performance on these nine test problems by obtaining the best IGD results on 22 out of 36 instances. GrEA shows effectiveness on 8 instances, which are the 5-objective instance of WFG1, 8objective instances of WFG4, WFG5, WFG6 and WFG9, 10objective instances of WFG1 and WFG3, and 15-objective instance of WFG3. I-DBEA and $\theta$-DEA outperform the other four algorithms on two instances respectively. In this test suite, RVGA does not show enough effectiveness. It is obviously that the best-performing algorithm over the WFG test suite is MOEA/CT and the second best algorithm is GrEA.

\section{REFERENCES}

[1] M. Asafuddoula, T. Ray, and R. Sarker, "A decomposition-based evolutionary algorithm for many objective optimization," IEEE Transactions on Evolutionary Computation, vol. 19, no. 3, pp. 445-460, 2015. 
TABLE IV

GD RESULTS ON UF1 TO UF7 AND IGD RESULTS ON UF8 TO UF10 OF THE FIVE ALGORITHMS. THE BEST MEAN FOR EACH PROBLEM IS SHOWN IN BOLD.

\begin{tabular}{ccccccc}
\hline & MOEA/CT & IDBEA & RVGA & $\theta$-DEA & GREA \\
\hline UF1 & $\mathbf{4 . 2 2 E - 0 4 ( 3 . 9 6 E - 0 4 )}$ & $1.19 \mathrm{E}-02(4.52 \mathrm{E}-03)^{+}$ & $1.34 \mathrm{E}-02(3.02 \mathrm{E}-03)^{+}$ & $1.32 \mathrm{E}-03(1.12 \mathrm{E}-03)^{+}$ & $4.45 \mathrm{E}-04(6.65 \mathrm{E}-04)^{+}$ & $7.42 \mathrm{E}-04(1.44 \mathrm{E}-03)^{+}$ \\
UF2 & $\mathbf{4 . 3 5 E - 0 4 ( 1 . 8 7 E - 0 4 )}$ & $5.56 \mathrm{E}-03(9.45 \mathrm{E}-04)^{+}$ & $9.53 \mathrm{E}-03(2.45 \mathrm{E}-03)^{+}$ & $3.01 \mathrm{E}-03(1.04 \mathrm{E}-03)^{+}$ & $4.45 \mathrm{E}-04(6.65 \mathrm{E}-04)^{-}$ & $2.29 \mathrm{E}-03(7.20 \mathrm{E}-04)^{+}$ \\
UF3 & $\mathbf{3 . 7 8 E - 0 3 ( 4 . 4 7 E - 0 3 )}$ & $9.91 \mathrm{E}-03(4.87 \mathrm{E}-03)^{+}$ & $4.66 \mathrm{E}-03(6.70 \mathrm{E}-03)^{+}$ & $3.91 \mathrm{E}-03(2.90 \mathrm{E}-03)^{+}$ & $4.23 \mathrm{E}-03(2.04 \mathrm{E}-03)^{+}$ & $3.88 \mathrm{E}-03(3.22 \mathrm{E}-03)^{-}$ \\
UF4 & $\mathbf{4 . 3 8 E - 0 3 ( 5 . 0 9 E - 0 5 )}$ & $7.35 \mathrm{E}-03(4.23 \mathrm{E}-04)^{+}$ & $1.36 \mathrm{E}-02(6.64 \mathrm{E}-04)^{+}$ & $6.14 \mathrm{E}-03(7.26 \mathrm{E}-04)^{+}$ & $4.66 \mathrm{E}-03(1.14 \mathrm{E}-04)^{+}$ & $5.23 \mathrm{E}-03(1.71 \mathrm{E}-04)^{+}$ \\
UF5 & $1.09 \mathrm{E}-01(7.83 \mathrm{E}-02)$ & $5.76 \mathrm{E}-02(2.29 \mathrm{E}-02)^{-}$ & $4.44 \mathrm{E}-02(2.75 \mathrm{E}-02)^{-}$ & $2.53 \mathrm{E}-02(1.10 \mathrm{E}-02)^{-}$ & $2.12 \mathrm{E}-02(1.27 \mathrm{E}-02)^{-}$ & $\mathbf{5 . 2 3 E}-03(1.71 \mathrm{E}-04)^{-}$ \\
UF6 & $2.31 \mathrm{E}-01(2.92 \mathrm{E}-02)$ & $3.55 \mathrm{E}-02(1.88 \mathrm{E}-02)^{-}$ & $2.83 \mathrm{E}-02(1.72 \mathrm{E}-02)^{-}$ & $1.14 \mathrm{E}-02(3.38 \mathrm{E}-03)^{-}$ & $\mathbf{8 . 5 4 E - 0 3 ( 2 . 7 7 E - 0 3})^{-}$ & $1.16 \mathrm{E}-02(1.01 \mathrm{E}-02)^{-}$ \\
UF7 & $\mathbf{7 . 6 4 E - 0 4 ( 7 . 1 0 E - 0 4 )}$ & $8.04 \mathrm{E}-03(4.48 \mathrm{E}-03)^{+}$ & $1.08 \mathrm{E}-02(3.41 \mathrm{E}-03)^{+}$ & $7.81 \mathrm{E}-04(3.26 \mathrm{E}-04)^{+}$ & $8.20 \mathrm{E}-04(3.68 \mathrm{E}-04)^{+}$ & $1.16 \mathrm{E}-02(1.01 \mathrm{E}-02)^{+}$ \\
UF8 & $\mathbf{1 . 7 6 E - 0 1 ( 5 . 6 0 E - 0 2 )}$ & $3.91 \mathrm{E}-01(1.81 \mathrm{E}-01)^{+}$ & $3.24 \mathrm{E}-01(1.51 \mathrm{E}-02)^{+}$ & $2.59 \mathrm{E}-01(4.93 \mathrm{E}-03)^{+}$ & $4.92 \mathrm{E}-01(9.09 \mathrm{E}-02)^{+}$ & $2.54 \mathrm{E}-01(1.37 \mathrm{E}-02)^{+}$ \\
UF9 & $\mathbf{2 . 0 0 E - 0 1 ( 4 . 6 2 E - 0 2 )}$ & $3.99 \mathrm{E}-01(6.79 \mathrm{E}-02)^{+}$ & $3.66 \mathrm{E}-01(7.74 \mathrm{E}-02)^{+}$ & $3.51 \mathrm{E}-01(8.97 \mathrm{E}-02)^{+}$ & $3.08 \mathrm{E}-01(1.07 \mathrm{E}-01)^{+}$ & $3.31 \mathrm{E}-01(8.26 \mathrm{E}-02)^{+}$ \\
UF10 & $\mathbf{3 . 7 8 E - 0 1 ( 9 . 4 7 E - 0 2 )}$ & $5.23 \mathrm{E}-01(1.99 \mathrm{E}-01)^{+}$ & $5.78 \mathrm{E}-01(1.20 \mathrm{E}-01)^{+}$ & $3.85 \mathrm{E}-01(1.35 \mathrm{E}-01)^{+}$ & $4.37 \mathrm{E}-01(8.44 \mathrm{E}-02)^{+}$ & $4.20 \mathrm{E}-01(1.36 \mathrm{E}-01)^{+}$ \\
\hline$b / w / e / g m$ & & $8 / 2 / 0 / 6$ & $8 / 2 / 0 / 6$ & $8 / 2 / 0 / 6$ & $7 / 2 / 1 / 5$ \\
\hline
\end{tabular}

TABLE V

IGD Results of the fIVE Algorithms on DTLZ1, DTLZ2, DTLZ3, AND DTLZ4. The BEST MEAN For EACH PROBLEM IS SHOWN IN Bold.

\begin{tabular}{|c|c|c|c|c|c|c|c|}
\hline \multicolumn{3}{|c|}{ DTLZ Obj.(MaxGen) } & IDBEA & RVGA & $\theta$-DEA & GrEA & AR-MOEA \\
\hline \multirow{4}{*}{1} & $5(600)$ & $6.46 \mathrm{E}-01(9.58 \mathrm{E}-01)$ & $8.43 \mathrm{E}-01(7.18 \mathrm{E}-01)^{+}$ & 6.82E-02(1.40E-04) $)^{-}$ & $6.83 \mathrm{E}-02(1.87 \mathrm{E}-04)^{-}$ & $2.06 \mathrm{E}-01(1.17 \mathrm{E}-01)^{-}$ & $6.84 \mathrm{E}-02(2.46 \mathrm{E}-04)^{-}$ \\
\hline & $8(750)$ & $3.25 \mathrm{E}+01(1.69 \mathrm{E}+01)$ & $1.83 \mathrm{E}+00(1.12 \mathrm{E}+00)^{-}$ & $1.09 \mathrm{E}-01(2.71 \mathrm{E}-03)^{-}$ & $1.11 \mathrm{E}-01(7.62 \mathrm{E}-03)^{-}$ & $3.45 \mathrm{E}-01(4.77 \mathrm{E}-02)^{-}$ & $1.09 \mathrm{E}-01(1.58 \mathrm{E}-03)$ \\
\hline & $10(1000)$ & $3.76 \mathrm{E}+01(3.76 \mathrm{E}+01)$ & $2.81 \mathrm{E}+00(2.01 \mathrm{E}+00)^{-}$ & $1.51 \mathrm{E}-01(2.47 \mathrm{E}-03)^{-}$ & $1.56 \mathrm{E}-01(2.57 \mathrm{E}-02)^{-}$ & $3.79 \mathrm{E}-01(5.77 \mathrm{E}-02)^{-}$ & $1.56 \mathrm{E}-01(5.37 \mathrm{E}-03)^{-}$ \\
\hline & $15(1500)$ & $2.75 \mathrm{E}+01(1.49 \mathrm{E}+01)$ & $9.56 \mathrm{E}+00(6.52 \mathrm{E}+00)^{-}$ & $1.85 \mathrm{E}-01(6.21 \mathrm{E}-03)^{-}$ & $2.97 \mathrm{E}-01(3.71 \mathrm{E}-02)^{-}$ & $9.87 \mathrm{E}+00(1.46 \mathrm{E}+01)^{-}$ & $1.73 \mathrm{E}-01(1.51 \mathrm{E}-02)$ \\
\hline \multirow{4}{*}{2} & $5(350)$ & $2.02 \mathrm{E}-01(2.49 \mathrm{E}-03)$ & $2.12 \mathrm{E}-01(6.81 \mathrm{E}-05)^{+}$ & $2.12 \mathrm{E}-01(3.33 \mathrm{E}-05)^{+}$ & $2.12 \mathrm{E}-01(2.36 \mathrm{E}-05)^{+}$ & $2.14 \mathrm{E}-01(2.30 \mathrm{E}-03)^{+}$ & $2.13 \mathrm{E}-01(2.62 \mathrm{E}-04)^{+}$ \\
\hline & $8(500)$ & $1.10 \mathrm{E}+00(1.12 \mathrm{E}-01)$ & $3.92 \mathrm{E}-01(2.17 \mathrm{E}-02)^{-}$ & $3.87 \mathrm{E}-01(1.81 \mathrm{E}-04)^{-}$ & $3.87 \mathrm{E}-01(1.77 \mathrm{E}-04)^{-}$ & $3.80 \mathrm{E}-01(1.57 \mathrm{E}-03)^{-}$ & $3.88 \mathrm{E}-01(8.79 \mathrm{E}-04)^{-}$ \\
\hline & $10(750)$ & $2.08 \mathrm{E}+00(4.13 \mathrm{E}-01)$ & $1.24 \mathrm{E}+00(1.10 \mathrm{E}-08)^{-}$ & 5.07E-01(2.23E-02)- & $5.02 \mathrm{E}-01(9.69 \mathrm{E}-04)^{-}$ & $5.28 \mathrm{E}-01(4.89 \mathrm{E}-02)^{-}$ & 5.02E-01(4.49E-03) \\
\hline & $15(1000)$ & $1.21 \mathrm{E}+00(1.15 \mathrm{E}-01)$ & $1.29 \mathrm{E}+00(3.13 \mathrm{E}-04)^{+}$ & $9.02 \mathrm{E}-01(1.83 \mathrm{E}-01)^{-}$ & $7.13 \mathrm{E}-01(2.48 \mathrm{E}-02)^{-}$ & $6.62 \mathrm{E}-01(2.77 \mathrm{E}-02)^{-}$ & $6.76 \mathrm{E}-01(1.23 \mathrm{E}-02)^{-}$ \\
\hline \multirow{4}{*}{3} & $5(1000)$ & $1.10 \mathrm{E}+01(9.71 \mathrm{E}+00)$ & $2.47 \mathrm{E}+00(7.35 \mathrm{E}+00)^{-}$ & $2.13 \mathrm{E}-01(5.68 \mathrm{E}-04)^{-}$ & $2.13 \mathrm{E}-01(5.75 \mathrm{E}-04)^{-}$ & 7.47E-01(2.13E-01)- & $2.14 \mathrm{E}-01(1.89 \mathrm{E}-03)^{-}$ \\
\hline & $8(1000)$ & $1.73 \mathrm{E}+01(1.47 \mathrm{E}+01)$ & $1.21 \mathrm{E}+00(4.52 \mathrm{E}-04)^{-}$ & $3.88 \mathrm{E}-01(1.44 \mathrm{E}-03)^{-}$ & $5.15 \mathrm{E}-01(2.04 \mathrm{E}-01)^{-}$ & $1.78 \mathrm{E}+00(7.54 \mathrm{E}-01)^{-}$ & $4.04 \mathrm{E}-01(1.36 \mathrm{E}-02)^{-}$ \\
\hline & $10(1500)$ & $1.98 \mathrm{E}+01(1.03 \mathrm{E}+01)$ & $1.24 \mathrm{E}+00(1.27 \mathrm{E}-04)^{-}$ & $5.04 \mathrm{E}-01(6.05 \mathrm{E}-03)-$ & $5.49 \mathrm{E}-01(8.87 \mathrm{E}-02)^{-}$ & $2.13 \mathrm{E}+00(1.27 \mathrm{E}+00)^{-}$ & $5.33 \mathrm{E}-01(1.35 \mathrm{E}-02)$ \\
\hline & $15(2000)$ & $1.95 \mathrm{E}+01(1.57 \mathrm{E}+01)$ & $1.33 \mathrm{E}+01(2.46 \mathrm{E}+01)^{-}$ & $7.90 \mathrm{E}-01(1.66 \mathrm{E}-01)^{-}$ & $9.28 \mathrm{E}-01(5.38 \mathrm{E}-02)^{-}$ & $1.51 \mathrm{E}+02(3.75 \mathrm{E}+01)^{+}$ & $7.63 \mathrm{E}-01(3.73 \mathrm{E}-02)$ \\
\hline \multirow{4}{*}{4} & $5(1000)$ & $2.04 \mathrm{E}-01(5.10 \mathrm{E}-02)$ & $5.39 \mathrm{E}-01(1.90 \mathrm{E}-01)^{+}$ & $2.30 \mathrm{E}-01(5.63 \mathrm{E}-02)^{+}$ & $4.12 \mathrm{E}-01(8.34 \mathrm{E}-06)^{+}$ & $2.46 \mathrm{E}-01(7.63 \mathrm{E}-02)^{+}$ & $2.68 \mathrm{E}-01(1.09 \mathrm{E}-01)^{+}$ \\
\hline & $8(1250)$ & $4.12 \mathrm{E}-01(4.75 \mathrm{E}-03)$ & $6.35 \mathrm{E}-01(1.55 \mathrm{E}-01)^{+}$ & $4.48 \mathrm{E}-01(6.36 \mathrm{E}-02)^{+}$ & $3.87 \mathrm{E}-01(4.38 \mathrm{E}-05)^{-}$ & $3.81 \mathrm{E}-01(1.62 \mathrm{E}-03)^{-}$ & $3.87 \mathrm{E}-01(1.45 \mathrm{E}-04)^{-}$ \\
\hline & $10(2000)$ & $5.12 \mathrm{E}-01(2.98 \mathrm{E}-03)$ & $6.93 \mathrm{E}-01(1.16 \mathrm{E}-01)^{+}$ & $5.19 \mathrm{E}-01(3.28 \mathrm{E}-02)^{+}$ & $5.01 \mathrm{E}-01(4.49 \mathrm{E}-04)^{-}$ & $5.17 \mathrm{E}-01(2.43 \mathrm{E}-02)^{+}$ & $5.04 \mathrm{E}-01(9.07 \mathrm{E}-03)^{-}$ \\
\hline & $15(3000)$ & $1.71 \mathrm{E}+00(1.64 \mathrm{E}-01)$ & $1.38 \mathrm{E}+00(7.88 \mathrm{E}-02)^{-}$ & $7.93 \mathrm{E}-01(5.03 \mathrm{E}-02)^{-}$ & $6.96 \mathrm{E}-01(1.54 \mathrm{E}-04)^{-}$ & $6.17 \mathrm{E}-01(1.25 \mathrm{E}-02)^{-}$ & $7.03 \mathrm{E}-01(1.43 \mathrm{E}-02)^{-}$ \\
\hline \multicolumn{3}{|c|}{$b / w / e / g m$} & $6 / 10 / 0 /-4$ & $4 / 12 / 0 /-8$ & $2 / 14 / 0 /-12$ & $4 / 12 / 0 /-8$ & $2 / 14 / 0 /-12$ \\
\hline
\end{tabular}

[2] R. Cheng, Y. Jin, M. Olhofer, and B. Sendhoff, "A reference vector guided evolutionary algorithm for many-objective optimization," IEEE Transactions on Evolutionary Computation, vol. 20, no. 5, pp. 773-791, 2016.

[3] K. Deb, L. Thiele, M. Laumanns, and E. Zitzler, "Scalable test problems for evolutionary multiobjective optimization," Evolutionary Multiobjective Optimization. Theoretical Advances and Applications, pp. 105-145, 2005.

[4] S. Huband, P. Hingston, L. Barone, and L. While, "A review of multiobjective test problems and a scalable test problem toolkit," IEEE Transactions on Evolutionary Computation, vol. 10, no. 5, pp. 477-506, 2006.

[5] Y. Tian, R. Cheng, X. Zhang, F. Cheng, and Y. Jin, "An indicator based multi-objective evolutionary algorithm with reference point adaptation for better versatility," IEEE Transactions on Evolutionary Computation, vol. PP, no. 99, pp. 1-1, 2017.

[6] Y. Tian, R. Cheng, X. Zhang, and Y. Jin, "Platemo: a matlab plat- form for evolutionary multi-objective optimization," arXiv preprint arXiv:1701.00879, 2017.

[7] S. Yang, M. Li, X. Liu, and J. Zheng, "A grid-based evolutionary algorithm for many-objective optimization," IEEE Transactions on Evolutionary Computation, vol. 17, no. 5, pp. 721-736, 2013.

[8] Y. Yuan, H. Xu, B. Wang, and X. Yao, "A new dominance relationbased evolutionary algorithm for many-objective optimization," IEEE Transactions on Evolutionary Computation, vol. 20, no. 1, pp. 16-37, 2016.

[9] Q. Zhang, A. Zhou, S. Zhao, P. N. Suganthan, W. Liu, and S. Tiwari, "Multiobjective optimization test instances for the cec 2009 special session and competition," University of Essex, Colchester, UK and Nanyang technological University, Singapore, special session on performance assessment of multi-objective optimization algorithms, technical report, vol. 264, 2008. 


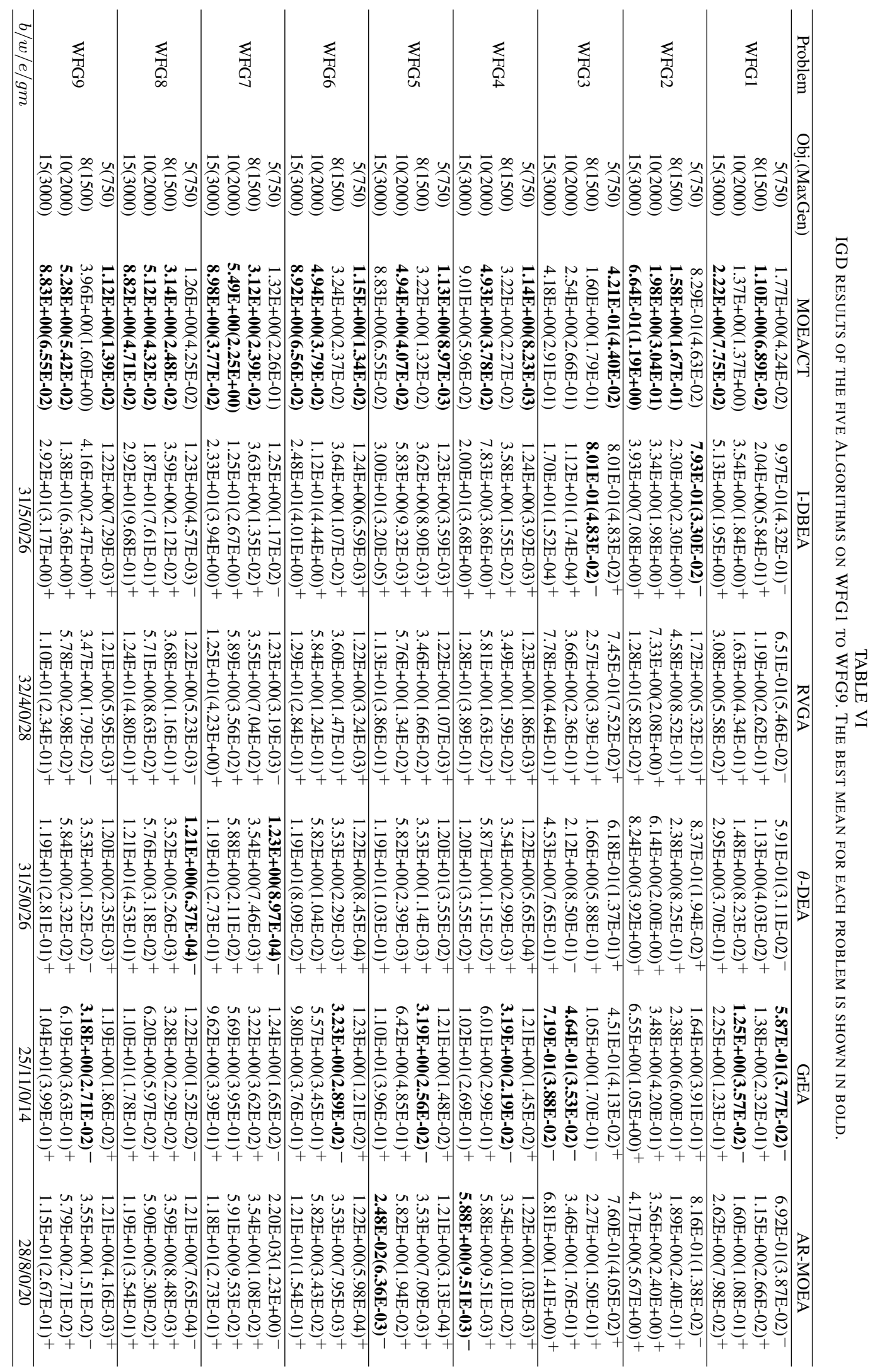

